Florida International University FIU Digital Commons

3-24-2014

\title{
Death Rituals in the New Diaspora: Funerals in the Lives of Ghanaians in South Florida
}

Evelyn E. Arhin-Sam

earhi001@fiu.edu

DOI: $10.25148 /$ etd.FI14040838

Follow this and additional works at: https://digitalcommons.fiu.edu/etd

Part of the Other Religion Commons

\section{Recommended Citation}

Arhin-Sam, Evelyn E., "Death Rituals in the New Diaspora: Funerals in the Lives of Ghanaians in South Florida" (2014). FIU Electronic Theses and Dissertations. 1195.

https://digitalcommons.fiu.edu/etd/1195

This work is brought to you for free and open access by the University Graduate School at FIU Digital Commons. It has been accepted for inclusion in FIU Electronic Theses and Dissertations by an authorized administrator of FIU Digital Commons. For more information, please contact dcc@fiu.edu. 


\title{
FLORIDA INTERNATIONAL UNIVERSITY \\ Miami, Florida
}

\section{DEATH RITUALS IN THE NEW DIASPORA: FUNERALS IN THE LIVES OF GHANAIANS IN SOUTH FLORIDA}

\author{
A thesis submitted in partial fulfilment of the \\ requirements for the degree of \\ MASTER OF ARTS \\ in \\ RELIGIOUS STUDIES
}

by

Evelyn Efua Arhin-Sam

2014 
To: Dean Kenneth G. Furton

College of Arts and Sciences

This thesis, written by Evelyn Efua Arhin-Sam, and entitled Death Rituals in the New Diaspora: Funerals in the Lives of Ghanaians in South Florida, having been approved in respect to style and intellectual content, is referred to you for judgment.

We have read this thesis and recommend that it be approved.

Christine Gudorf

Ana Maria Bidegain

Albert K. Wuaku, Major Professor

Date of Defense: March 24, 2014

Dean Kenneth G. Furton

College of Arts and Sciences

Dean Lakshmi N. Reddi

University Graduate School

Florida International University, 2014 


\section{DEDICATION}

I dedicate this thesis to my mother, Mary Ama Nyarkoh and my maternal grandmother, Esi Kitiwaa, for providing me with the oral accounts on Akan funeral in Ghana. 


\section{ACKNOWLEDGMENT}

I am duly thankful to my committee members, Dr. Christine Gudorf, Dr. Ana Maria Bidegain and Dr. Albert Wuaku for their constant guidance and support. I am most grateful to Dr. Gudorf for her editing and constructive feedbacks in shaping my flow of thought. And also, for availing her apartment during my study at FIU and staying up late to listen to my field work experiences when I get back from the field. I am indebted to Dr. Bidegain for her constant smiles and encouragement and feedbacks throughout the research. To my major supervisor, Dr. Wuaku (Efo), I say akpe. Not only was he constructive in shaping this thesis, but also, he helped me in carving the thesis topic. I am also grateful for his occasional visits to the Association meetings. It really encouraged me to continue with the research.

I am also grateful to all the professors at the Religious Studies Department especially, Dr. Oren Stier. Your constant email reminders kept me on my toes. My special appreciation goes to my graduate colleagues, for the many discussions regarding our research and the constant reminders to keep the candle burning, especially Alex (ashe), Katie (Baaku), Ellen, Sigi, Alfonso, Andreas and Mark.

I am also grateful to Rev. Dr. Elom Dovlo (University of Ghana) for his support.

I am indebted to the members of the United Ghanaians Association of South Florida (UGASF). Thanks to the immediate past president, Pastor Bismark OmaneAchamfour for introducing me to the other members of the Association. I am also grateful to Dr. Edmund Abaka (University of Miami) and his wife for giving me rides to UGASF's monthly meetings and funeral services in Fort Lauderdale. I am also grateful to the Kakrah family for allowing me to spend a night in their home while gathering data. 
Finally, I am grateful to my husband, Seth, for his encouragement and constant reminders. To these people, as the saying goes in Akan, "if you hear the crowing of the rooster at the dawn of tomorrow" know that I am saying, thank you, akpe, medasi and ayekoo. 
ABSTRACT OF THE THESIS

DEATH RITUALS IN THE NEW DIASPORA: FUNERALS IN THE LIVES OF

GHANAIANS IN SOUTH FLORIDA

\author{
by \\ Evelyn Efua Arhin-Sam \\ Florida International University, 2014 \\ Miami, Florida \\ Professor Albert K. Wuaku, Major Professor
}

This thesis addresses the lack of attention to practices that take place in settings not considered primarily religious, such as life-cycle rituals in the growing body of literature on religious practices of recently emerging African diaspora communities in the West. The thesis argues that these practices are not only filters for indigenous African religious beliefs but also furnish for African migrants contexts that perform functions similar to those performed by the formal African diaspora religious institutions. Using ethnography, the study investigated the role of death rituals in the lives of Ghanaian members of the United Ghanaians Association of South Florida. The findings show that funerals organized in South Florida for relatives of members of the Association enable this transmigrant community to participate in the lives of their relatives in Ghana. Funerals also furnish for these migrants contexts for performing aspects of their culture helping to cultivate a shared sense of being together or identity, in the process. The study suggests that to understand the full dynamics of African migrant religious experience, a respectful attention must be paid to all the rites of passage that African migrants perform in the West, not only those within formal religious institutions. 


\section{TABLE OF CONTENTS}

CHAPTER

PAGE

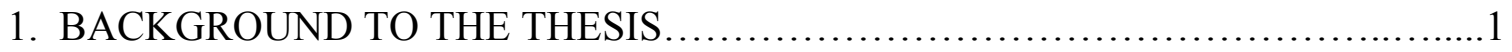

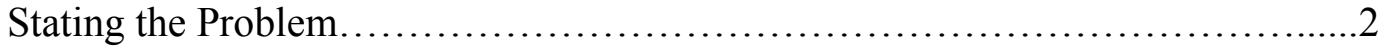

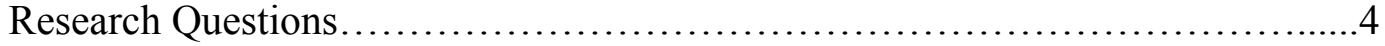

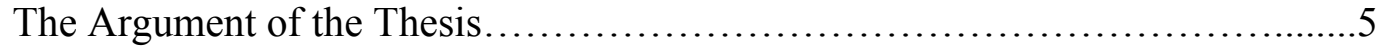

Method of Data Collection..................................................

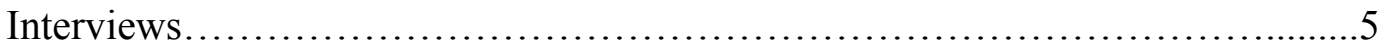

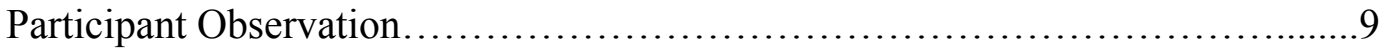

Participating in the Monthly Meetings........................................

Participating in Other Social Events......................................... 10

Participating in Funeral Rituals in South Florida..................................12

Review of Activities in the Media...............................................13

Theoretical Perspectives/Concepts........................................13

Literature Review: Religious Expressions in the New Africa diaspora..............17

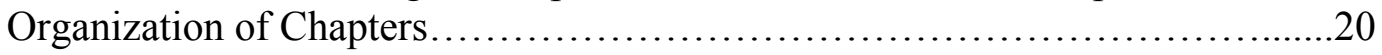

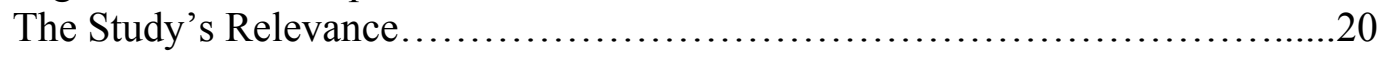

\section{CONTEXTUALIZING DEATH AND DYING IN THE GHANAIAN}

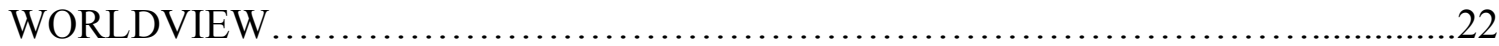

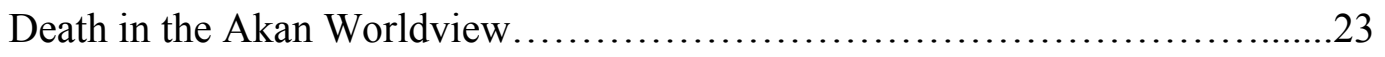

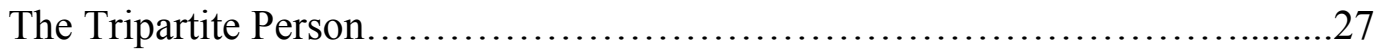

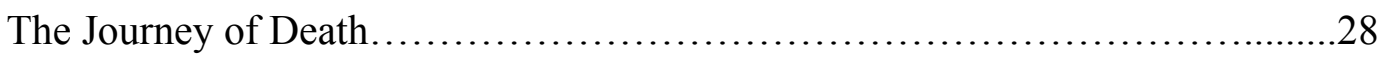

Post-Mortem Rituals............................................................

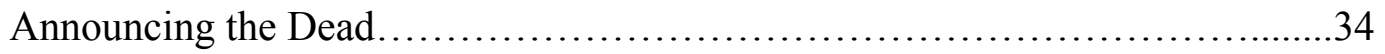

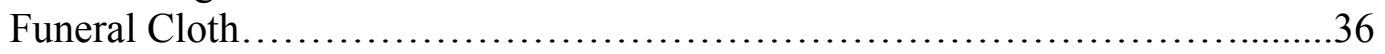

The Influence of Western Modernity, Globalization and Funerals and the Involvement of Ghanaians in the Diaspora.....................................40

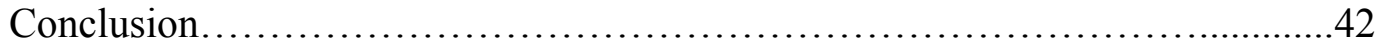

3. UNITED GHANAIANS ASSOCIATION OF SOUTH FLORIDA......................44

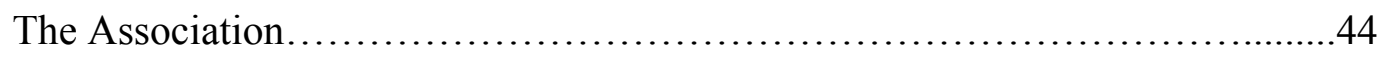

How the Association Originated...........................................48

Abrokyire / America.........................................................51

Memoirs of Our Departing and Our Transit...................................55

Life in America: Living in South Florida........................................56

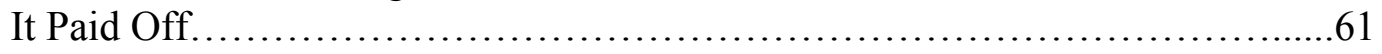

Serving as a Linkage to Ghana.............................................62

Coping/ Settling as Trans-Migrants in America.................................64

Economic and Other Supports.............................................66

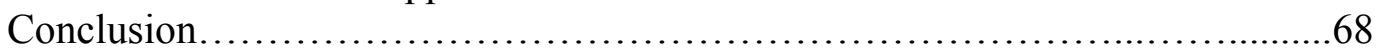


4. FUNERALS IN THE LIVES OF GHANAIANS IN SOUTH FLORIDA...............69

It is Our Life.............................................................. 70

Identity Creation, Cultural Preservation \& Promotion...............................70

Funeral Cloths......................................................... 75

Using Photos of the Dead............................................... 80

Performing Ghanaian Identity through Food at Funerals.........................83

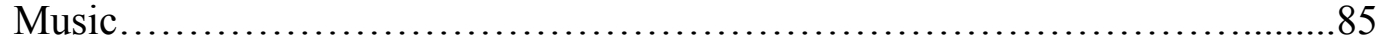

Dance/Cultural Display................................................. 86

Language............................................................. 90

Conclusion: Can We Survive?...........................................92

5. CONCLUDING THE THESIS .............................................. 94

Major Findings and Discussions....................................... 94

Recommendation: Areas for Further or Future Research.......................99

REFERENCES............................................................ 101 


\section{LIST OF FIGURES}

FIGURES

PAGE

1. Me (on the left hand side wearing a hat) with some members

of the Association.

2. A Flyer Announcing Ghana's 56 ${ }^{\text {th }}$ Independence Anniversary Celebration in South Florida.

3. An image of the Akan Symbol, owuoatwedea- the Ladder of Death.

4. Some Ghanaian Funeral Posters. On the right is the Funeral Poster of Ghana's late President, John Evans Atta Mills who died in 2012 ...................................

5. A Picture of Mourners in Black and Red Funeral Cloths..............................37

6. A Mourner in a White Funeral Cloth with Black Pattern or Design........................38

7. Image of the Head of the late President of Ghana, Atta Mills, printed on the Cloth

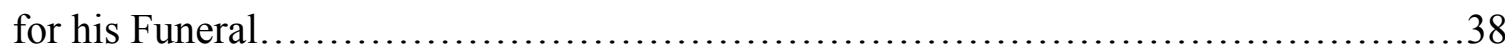

8. The Akan Nkonsonkonson (chain link) Symbol, the Emblem

of the Association.

9. A picture of some members (moframofra and sankofa groups) performing the Akan Adowa dance.

10. Front View of the Broward County Library where the Association met at the time of the Research.

11. The president and the vice president of the Association making a Funeral Donation

to a Bereaved Member in South Florida.

12. Symbolic gathering of Ghanaian Traditional Rulers and Ritual Specialists dressed in Ghanaian Royal Regalia in South Florida.

13. One of the Association members collecting donations from other members on behalf of a bereaved family during a funeral in Fort Lauderdale.

14. The President and the Vice President of the Association giving the funeral donation (the envelope in hand) to a bereaved member on behalf of the Association

15. One of the women dressed in a Ghanaian kaba and slit style. .76 
16. I (on the left hand side) together with one of the women in a traditional Ghanaian red and black funeral cloth, kaba and slit........................................... 77

17. Members in traditional funeral cloths (red, black and white) during a funeral in South Florida.

18. A picture of a deceased (while alive) placed infront of the mourners and sympathizers during a funeral celebration in Fort Lauderdale, South Florida .80

19. Women serving the food during a funeral celebration in Fort Lauderdale .83

20. Some Ghanaian food at a funeral in Fort Lauderdale, South Florida.

21. On the left is a picture of a Ghanaian cultural/singing group. On the right is an individual singing to console a bereaved family during a funeral in Fort Lauderdale.

22. A picture of moframofra and sankofa groups during a function in South Florida .....87

23. A picture of Auntie Efua performing the adowa dance during a funeral in

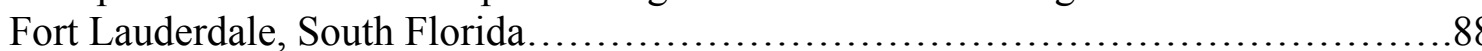

24. Section of some members of the Royal House of Chiefs and Queens during a funeral in Fort Lauderdale. 


\section{CHAPTER 1}

\section{BACKGROUND TO THE THESIS}

There is a growing literature on religious flows from Africa to the diaspora in the West in accompaniment with population flows. ${ }^{1}$ The bulk of this literature focuses attention on the ways in which religious flows from African communities function as mechanisms of adjustment for African migrants in their western host communities. Other researchers explore how these religious practices generate contexts in which linkages between the African homelands and migrant host communities are fostered. Identifying recent African migrants in the West as "trans-migrants" who live "between and betwixt" their African homelands and the diasporas, this literature demonstrates how religious traditions facilitate these homeland-diaspora interactions. ${ }^{2}$ However, thus far, this emerging research has focused attention on formal African institutionalized religious practices only. ${ }^{3}$ Specifically, indigenous African Pentecostalism and Islam in the West have

\footnotetext{
${ }^{1}$ Valentina Mazzucato, "Origins and Destination of Remittances in Ghana" in At Home in the World? International Migration and Development in Contemporary Ghana and West Africa, ed. Takyiwaa Manih, (Accra, GH: Sub-Saharan Publishers, 2005); Valentina Mazzucato et. al, "Transnational Migration and the Economy of Funerals: Changing Practices in Ghana" Development and Changes 37: 5 (2006); Jacob K. Olupona, "Introduction" in African Immigrant Religions in America, eds. Jacob K. Olupona, \& Regina Gemiggnani, (New York: New York University Press, 2007); Steve Tonah, "Ghanaians Abroad and Their Ties Home: Cultural and Religious Dimensions of Transnational Migration" a paper presented at the Center for Interdisciplinary Research, Bielefeld, Germany, May 31-June 1, 2007; Moses O. Biney, From Africa to America: Religion and Adaptation Among Ghanaian Immigrants in New York (New York \& London: New York University Press, 2011).

2 Akintunde Akinade, "Non-Western Christianity in the Western World: African Immigration Churches in the Diaspora" in African Immigrant Religions; Jacob K. Olupona, "Communities of Believers: Exploring African Immigrant Religion in the United States" in African Immigrant Religions; Wisdom J. Tetteh, "Transnationlism, Religion, and the African Diaspora in Canada: An Examination of Ghanaians and Ghanaian Churches" in African Immigrant Religions; Biney, From Africa to America.
}

3 By institutionalized religions/practices, I am referring to those institutions that traditionally have been seen as the primary settings for religious expressions, such as churches, mosques, and shrines among others. 
received attention from these researchers in the West. More important, there is a lack of attention to practices that take place in settings not considered primarily religious such as African religious practices in the context of life-cycle rituals in the West: birth, marriage and funerals. Yet, these practices are not only filters for indigenous African religious beliefs but also furnish for African migrants contexts to perform functions similar to those performed by the institutionalized religions.

One of such African cultural practices which provide a context for African religious practices in the West is funerals or death rituals. Funerals in particular generate a context in which African diasporic communities integrate periodically, create and perform identities in their newly adopted Western homes. They also generate a context in which African "trans-migrants" in the West are able to participate in the lives of their homelands. The focus of this thesis is how funerals, whether performed in Ghana or South Florida, mediate these functions in the lives of Ghanaian migrants living in South Florida.

\section{Stating the Problem}

Specifically, I focus on the United Ghanaians Association of South Florida (henceforth referred to as UGASF). The UGASF is a 501 (c) (3) non-profit association incorporated in 1993 in Fort Lauderdale, with regular membership approximating about forty. Although there are varied accounts regarding how this Association originated, the consensus among members is that the death of a Ghanaian migrant prompted its beginning in 1992. The death of the mother-in-law of a Ghanaian migrant, Cliff Lartey (now deceased) in 1992 at Fort Lauderdale, and the high cost incurred in transporting the body to Ghana and the subsequent burial, prompted the Ghanaian community in South 
Florida to form an association. Among other things, the Association was to "help cover the cost of funerals, and provide emotional support for the bereaved members." ${ }^{4}$ The socio-economic cushioning and support was deemed to be necessary in light of the high cost of funerary rituals both in the host country, America, and the homeland, Ghana, and the isolated lives Ghanaians live as migrants in South Florida. The fact that it was a funeral that occasioned the beginning of the Association underscores the crucial role of funerals as a symbol of this community's integration. A bereaved member's dead relative does not have to have been living in South Florida for him or her to receive support from the Association. The support also extends to the funerals of dead relatives back in the homeland. Thus, in the context of funerals, the Association also participates in the lives of family members back in the homeland.

Over the years, the Association has extended its aim of cushioning or supporting bereaved members to the promotion of "the well-being and social prosperity of Ghanaians, fostering the unity and strength of South Floridian Ghanaians as a group, and celebrating the group's cultural diversity in South Florida." " Using the importance of funerals in the United Ghanaians Association of South Florida as a case study, the thesis investigates how the funeral, a rite of passage and a practice not considered primarily religious facilitates community integration, identity creation and generates a context for Ghanaian trans-migrants in South Florida to participate in the lives of relatives back at home.

\footnotetext{
4 "United Ghanaians Association of South Florida," http://www.ghanasouthflorida.org, [accessed, May 3 2013].

5 "United Ghanaians Association of South Florida," http://www.ghanasouthflorida.org, [accessed, May 3 2013].
} 


\section{Research Questions}

The research on which the thesis is based sought answers to the following questions;

- What role do funerals play in the lives of Ghanaian trans-migrants in South Florida?

- What aspects of Ghanaian religious beliefs are filtered into the USA through the practice of funerals?

- How do funerals generate a context for Ghanaian ethnic identity creation and foster linkages among Ghanaians in South Florida and between them and the homeland?

\section{The Argument of the Thesis}

The thesis argues that just like the institutional African diasporic religious groups attracting the attention of scholars, African practices that take place in settings not considered primarily religious such as funerals also generate a context in which African diasporic community integration is fostered, ethnic identities are created, social capital is garnered and deployed, and linkages with the homeland are facilitated. The data show that although not very regular practices, Ghanaian funerals in South Florida cushion the impact of the death on the bereaved and provide avenues for important social contact for Ghanaian migrants. As trans-migrants, that is, people who live their lives both in the homeland and the diaspora, Ghanaian migrants are able to participate in the lives of their relatives back home in the context of funerals (both those held at home and in South Florida). Migrants send remittances to sponsor funerals; many need to travel back home when there is a death in the family. Should a migrant be buried in South Florida, relatives travel from the homeland to participate in the funeral. The functions the funerals play in the lives of Ghanaian migrants, then, are akin to those that institutionalized religious traditions play in the lives of Ghanaians in the diaspora. I suggest that the study of the 
place of religion in the lives of recent African migrants in the USA cannot be complete without an exploration of African practices such as rites of passage that take place in settings not considered primarily religious.

\section{Method of Data Collection}

I used UGASF as a case study because it is the only Ghanaian association in Florida. Also, its origin is linked with an emphasis on supporting trans-migrant Ghanaians with the cost of post-death rituals both in the diaspora and the homeland. I used a triangulation of ethnographic approaches in the data collection. Triangulation is the process of corroborating evidence from different methods of data collection to ensure the accuracy of the information gathered. ${ }^{6}$ I employed both primary and secondary methods of data collection. These approaches were triangulated to "ensure the accuracy of the information gathered since information was not drawn from a single source $\ldots$ or process of data collection." ${ }^{77}$ Secondary sources include scholarly materials.

Interviews. Interviews involved me meeting with respondents, asking specific questions in order to find answers to the research problem. The questions revolved around, but were not limited to, issues regarding their experience(s) as trans-migrants; why they joined UGASF; and their funeral ritual experience(s) in Florida, Ghana or both. In all, I interacted with twenty adult members under the following categories;

- Leaders (past and present) of UGASF

\footnotetext{
6 Vincent A. Anfara, et al. "Qualitative Analysis on Stage: Making the Research Process More Public," http://www.edr.sagepub.com/content/31/7/28 [accessed, June 12 2011].

7 Vincent A Anfara, et al. "Qualitative Analysis on Stage: Making the Research Process More Public." http://www.edr.sagepub.com/content/31/7/28 [accessed, June 12 2011].
} 
- Members who have performed funeral rituals either in South Florida or in Ghana

- Individuals who do not belong to the above categories but have participated in Ghanaian funerals either in South Florida or in Ghana.

Although all the members spoke and understood the English language, most of them preferred to be interviewed in one or another Ghanaian language, or in a mixture of a Ghanaian language with the English language. The most common Ghanaian language used as part of the interview was $T w i{ }^{8}$ I noticed that most of the members, especially, the elderly, expressed themselves better in Twi during our conversations. A typical conversation with a respondent would begin with the reading of the IRB verbal consent form, which I had to translate into the Twi sometimes to be sure they comprehended the content. I also wanted to make sure my respondents were aware of the risks and benefits involved in the research. Finally, participants needed to know they were not obliged to be part of the research; they can withdraw at any time. Fortunately, I did not encounter any respondent withdrawing from the research. I guess one of the reasons is that almost none of the members saw me as researcher, but rather as a Ghanaian young woman trying to "make it" in South Florida/America. They seemed sympathetic and viewed their participation in the research as their contribution to my success as a student. The sympathetic attitude was really helpful because members were more than willing to help with whatever I needed for the research. Many members called even after our interactions to find out how I was doing and if they could be of any further assistance.

8 Twi is a language spoken by a section of the Akan ethnic group in Ghana. It is the most common language spoken in Ghana, especially in the Southern part of the country. Most of the members of the Association belong to the Akan ethnic group. This explains why Twi was used as part of my interviews. 
My interactions with a member often ended up with an introduction or the mentioning of another family who the interviewee thought would be helpful for my research. For instance, during my interview with Auntie Awo (80), one of the elderly women in the Association, she indicated, "you know if this is an academic work, you might want to Ama, the Owuo family. They will be a useful resource for the studies. Eii, you know Ekua just returned from Ghana... she went for her sister's funeral... this is her number ... you might want to talk to her."

Such conversations led directly to my meeting with the Ansah family, who became my most important informants during the research. I came to view this family as the "information centre" of the Association. The family was always ready and willing to provide any information (past, present) one would require of the Association or about any member in it. Their home in Kendall, a suburb of Miami, is an important venue for the gathering of members of the Association. The Kendall home is "the place" for members who want to trade stories about happenings in Miami, Ghana, and around the globe and participate in "Associational gossip." The Ansah family is made up of the couple (Mr. \& Mrs. Ansah) and their two children, Ama and Kojo. ${ }^{10}$ As one of the earliest Ghanaians to settle in South Florida, a founding member of the Association and one of the Association's former presidents, Mr. Ansah is an important source of knowledge about the Ghanaian community in South Florida. But Mr Ansah's status as a chief of a Ghanaian village also explains the respect members accord him. Every day the Ansahs

\footnotetext{
9 Auntie Awo, interviewed July 82013.

${ }^{10}$ Ama is the Akan name for females born on Saturday. Kojo is the Akan name for males born on Monday. This is usually referred to as "soul names." Each Ghanaian has a soul name based on the day of birth. This determines an individual's character trait.
} 
receive a string of visitors from the Ghanaian community, the majority of whom are in need of casual advice from the chief on some challenge facing them. In addition, because the family's home has a big yard, the Association holds many of its social events here, making it possible for the Ansah family to interact with almost every member. The closeness between my age and Ama's, and the fact that the Ansah's spoke Twi, my dialect, made me feel very much at home with them.

Having come to view the Ansahs as a repository of knowledge about the Ghanaian community in South Florida, I made a point of sitting close to them during the monthly meetings of the Association. Sitting with them gave me the opportunity to learn the names of other members, their occupations, where they live, and also whether they had been involved in any post-death rituals either in South Florida or in Ghana.

I did not really "make appointments" for interviews with most of the members. Most interviews took place in informal settings: in their homes, on the phone, while driving with them, socializing with them after meetings, at social events and funeral services. For instance, a casual conversation with the Kumah family while riding home with them one Sunday afternoon after church provided me with informative data. In situations where members did not have enough time for conversations during our interactions, they would ask me to call them either on their cell phones or through Skype (for members I am friends with on Skype) at a later date for a longer conversation. Thus, the use of technology was an important feature in my interviews.

The challenge with the technology, either the cell phone or Skype, was that since most of the interactions took place when the members were at home or doing something else in addition to the interview, they were constantly interrupted with family issues or 
calls from insurance companies, friends or relatives. In such instances, I had to excuse them so they could attend to other issues. This usually prolonged the anticipated time for an interview.

Participant Observation. According to Olov Dahlin, for a researcher "to be able to apprehend the insider view, it is important to interact and take an active role in the everyday life of the people studied, that is 'to be there' as much as possible." ${ }^{11}$ Following this lead, I participated in the Association's monthly meetings, social events and funeral rituals organized by the bereaved whenever there was a death either at home in Ghana or in South Florida. In all, I participated in three funeral rituals from July 2013 to January 2014.

1. Participating in the Monthly Meetings. My reason for participating in the monthly meetings was to gain a sense of the dynamics of these meetings, the issues addressed, how such issues inform members' sense of Ghanaian identity, and to get to know members of the community personally. The Association meets the first Saturday of every month from 7 p.m. to 9 p.m. at the Broward County Library in Fort Lauderdale. Prior to meetings, reminders in the form of emails are sent to members. Before attending my first meeting, I inquired about the date and venue from the then president of the Association [whose email I found at the Association's webpage]. I also had to pay dues (of $\$ 60$ from July 2013 to December 2013) as a new member of the Association.

The monthly meetings are times for, but not limited to, planning events the Association wants to organize during the year, raising concerns of members,

${ }^{11}$ Olov Dahlin, Zvinorwadza: Being a Patient in the Religious and Medical Plurality of the Mberengwa District, Zimbabwe (Frankfurt am Main: Peter Lang, 2002), 22. 
discussing social initiatives of the community, work and health-related issues. Names of members looking for work and apartments and other things are announced so that other members, in a position to do so, can help. Even though some members complained that the meeting proceedings need to be in a Ghanaian language, English is the language spoken at these meetings. The challenge with having the proceedings in a Ghanaian language is which Ghanaian language to use. There are at least three Ghanaian groups at the Association; Akans (Twi, Fante and Akwapim), ${ }^{12}$ Gas, and Ewes, with each group speaking a different language. The current resolution to the language diversity is the use of English as the lingua franca.

All the meetings begin and end with a Christian form of prayer said by the president or a nominee. After meetings, members socialize; often times I would observe clusters of members who speak the same language or who are friends engaging in conversations. The socialization time provided a good opportunity for me to interact with and get to know the members, talk about my research and secure dates for interviews. At other times I sought answers to some of my research questions in the context of our conversations during these interactions.

2. Participating in Other Social Events. As part of the Association's aim to re-create a sense of Ghanaian identity, it organizes social events, such a Ghanaian cultural festival, in order to perform aspects of Ghanaian culture through drumming, dancing or drama.

Fig. $1 \mathrm{Me}$ (on the left hand side wearing a hat) with some members of the Association; a Nigerian and a Jamaican at Ghana's $56^{\text {th }}$ Independence Anniversary Celebration in South Florida.

12 These are languages spoken within the Akan ethnic group. 


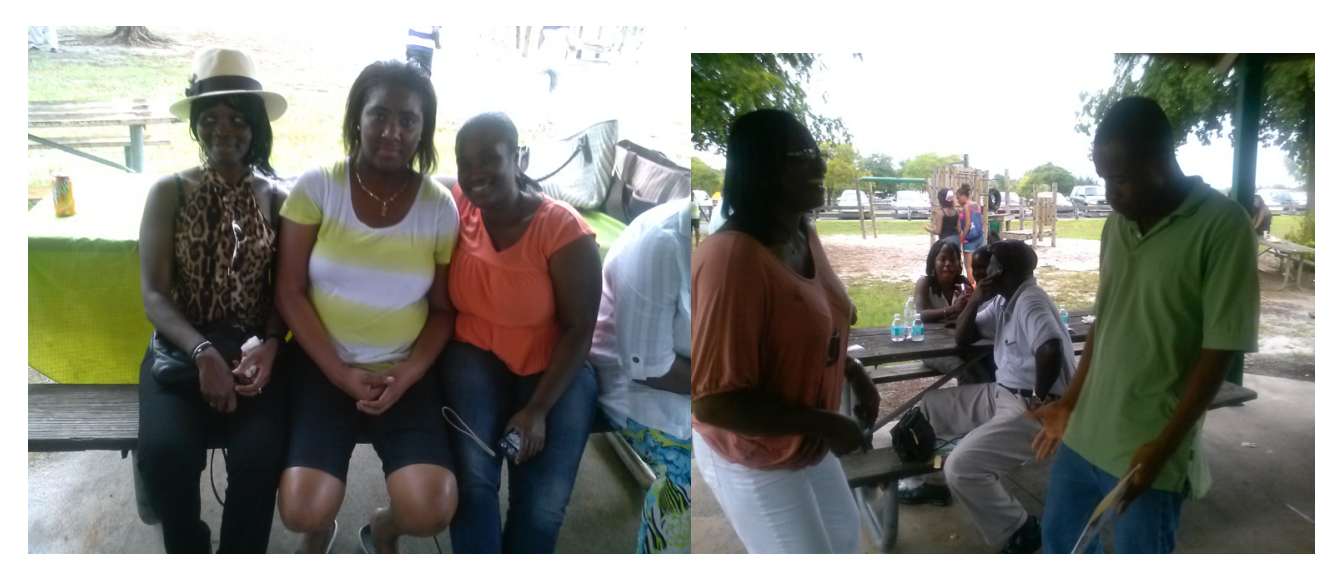

As part of the Association's trans-migrant status or continuous link with Ghana, it also organizes events to commemorate Ghanaian national events, often using these as an opportunity to showcase aspects of Ghanaian culture. For instance, the Association held an event to mark Ghana's $56^{\text {th }}$ Independence Celebration. Members dramatized a traditional Ghanaian marriage and held a royal procession of Ghanaian chiefs and queens. The objective of such dramatizations is to expose those I call "Ghanaian-Americans" (Ghanaians born in South Florida and have never been to Ghana) and other non-Ghanaians, to aspects of the Ghanaian heritage.

Fig. 2 A Flyer Announcing Ghana's $56^{\text {th }}$ Iindependence Anniversary Celebration in South Florida. 


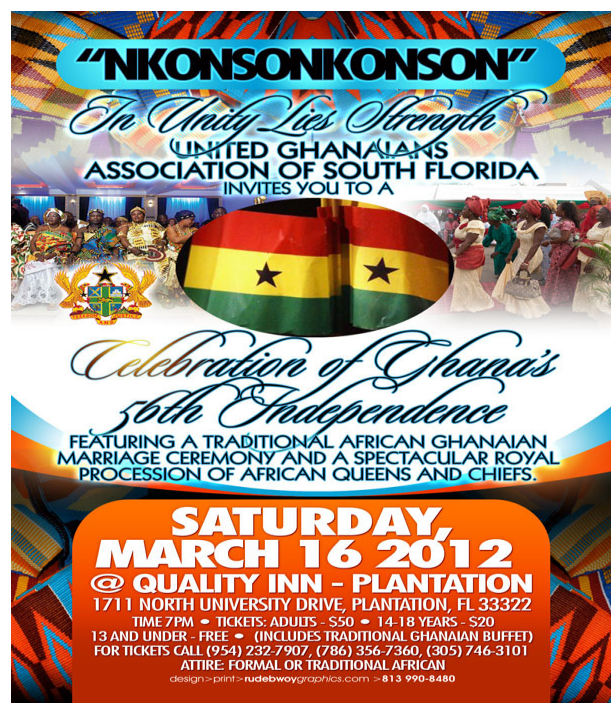

I used my participation in these events to make important social contacts and also to have conversations about Ghanaians' experience of life as migrants and the funerals they have been part of.

3. Participating in Funeral Rituals in South Florida. I participated in three postdeath rituals. In all three cases the death occurred in Ghana. Like the weekly meetings and other social events, the Association, apart from announcing impending funerals at the monthly meetings, also circulates emails with the date and the dress code for the funeral. All three funerals were held in Fort Lauderdale because the bereaved families lived there. The Association maintains the Ghanaian tradition of holding funerals on Saturday but, holds the services in the evening (from 7-11p.m.) instead of the normal morning service in Ghana because most of the members work on Saturday mornings. Participating in the funerals gave me a sense of those aspects of Ghanaian culture that have been infiltrated into the United States and also, of how funerals create a context for trans-migrants to participate in the lives of diasporans as well as relatives back home in Ghana. 
Review of Activities in the Media. I reviewed and analysed some of the activities or events posted on the Association's webpage, webpage, http://www.ghanasouthflorida.org and the face book page. The webpage has the history of the Association, names and contact information about executive members in the Association. It was actually at the website that I found the contact information of the then-president, who provided me access to other members. The webpage also has a record of past events and announcements of upcoming ones. On the basis of the information at the Association's webpage, I noticed how the Akan culture influences most of the activities the Association organizes. For instance, pictures of previous and most recent cultural events the Association had performed had a sense of the Akan identity, including the use of Akan kente cloth, the adowa dance (a common dance among the Akans) and the use of the Akan symbol, owuoatwedea (death ladder) as the symbol of the Association. Reviewing these events on the webpage, gave me some insight into the history of the Association and the activities it had been engaged in over the years.

\section{Theoretical Perspectives/Concepts}

The thesis engages the concepts of ethnic identity and simultaneity in analysing the data gathered. There is a general perception that "if contact with groups and individuals who are perceived as different from oneself is necessary in order to make ones' ethnic group relevant, then the context and process of immigration is a prime contributor to ethnicity." ${ }^{\prime 13}$ The context and process of immigration is a prime contributor to ethnicity because migration always involves the proximity of cultures other than one's own. Such

13 Anya P. Royce, Ethnic Identity: Strategies of Diversity, (Bloomington, IN: Indiana University Press, 1982), 108. 
proximity always generates a sense of "we feeling," leading to the urge in migrants to create an identity for themselves within the larger social context within which they find themselves.

According to Eugeen E. Roosens, ethnic identity is intrinsically linked with ethnicity. ${ }^{14}$ Anya P. Royce defines ethnic identity as "the sum total of feelings on the part of group members about whose values, symbols and common histories that identify them as a distinct group." 15 Such "distinctiveness" stems from past experiences such as nationalism, immigration, and colonialism, which have been redefined over time..$^{16}$ There is fluidity in this ethnic identification. ${ }^{17}$ This fluidity in its creation and performance among migrants creates space for new identities of the same people to be created, recreated and redefined. However, in the process of this redefinition, there is a conscious effort to preserve what members of the migrant group identify as its "original" identity. For Roosens, in order to preserve a group's identity and also to differentiate it from other similar groups, a social border is drawn between "itself and the other similar groups by means of cultural emblems and values that make it different in its own eyes and in the eyes of others."18 Adding to the above, Anya maintains, "No ethnic group can maintain a believable (viable) identity without signs, symbols and underlying values that point to a

14 Eugeen E. Roosens, Creating Ethnicity: The Process of Ethnogenesis, (London: Sage Publications, 1990), 15.

15 Royce, Ethnic Identity, 18.

16 Royce, Ethnic Identity, 2.

17 Royce, Ethnic Identity, 17.

18 Royce, Ethnic Identity, 12. 
distinctive identity." ${ }^{19}$ Jacob Olupona indicates that African ethnic identities in the USA are connected to migrants creating a quasi community of the homeland in the host country in "connection to, and remembrance of an African homeland."20

Such creation is complemented by an emphasis on the cultural values of the homeland, where, "community members emphasise the importance of speaking their languages and hearing it [sic] spoken, the chance to enjoy special food delicacies, services, and events often including ethnic markers such as flags and clothing styles... reference to cultural beliefs and values.."21 Religion plays a crucial role in this process. According to C. Eric Lincoln, the African religious cosmos is crucial in the creation and performance of African ethnic identity as it informs African values, and other ethnic markers. ${ }^{22}$

This thesis views Ghanaian migrants as an ethnic unit. Although they originate from different ethnicities in Ghana, they view themselves as a single group in South Florida, thereby creating a new Ghanaian ethnicity, the United Ghanaians Association of South Florida. This concept of ethnic identity is important in helping us to intellectually engage the process entailed in the creation of this Ghanaian community and the place of funerals in the process. In this thesis, particularly in Chapter 4, I demonstrate how funerals as a religious ritual provide context for the performance of aspects of Ghanaian

\footnotetext{
19 Royce, Ethnic Identity, 7.

20 Olupona "Introduction,"4.

21 Olupona, "Introduction," 4.

22 C. Eric Lincoln, "Black Religion and Racial Identity" in Racial and Ethnic Identity: Psychological Development and Creative Expression, eds. Herbert W. Harris et al. (New York/London: Routledge,1995), 211.
} 
culture such as music, drumming, food, dance, ways of dressing, even mannerisms in speaking, all of which contribute to a strong sense of being Ghanaian among the members.

Another concept relevant to this thesis is "simultaneity," as used by Peggy Levitt and Nina Schiller. Simultaneity is a concept whereby "migrants and their descendants remain strongly influenced by their continuing ties to their home country or by social networks that stretch across national borders." ${ }^{23}$ Simultaneity is important in understating the daily lives of migrants since their lives cannot be understood within national boundaries. The totality of the migrants' lives are shaped and influenced by the cultural traits, values and forms of physical interactions with the homeland. Migrants are involved in a multi-sited transnational social field. They, for instance, send remittances to family members or relatives in the homeland, engage in prayers or other religious activities on behalf of the homeland, and continue to fulfil other social or financial responsibilities or obligations towards the homeland. Simultaneity is very peculiar to migrants from third world countries to developed or Western countries. According to Valentina Mazzucato, such an engagement "enables linkages between dispersed people to tighten, new livelihood opportunities emerge, social institutions change, and hybrid identities develop." 24

\footnotetext{
23 Peggy Levitt \& Nina G. Schiller, "Conceptualizing Simultaneity: A Transnational Social Field a Perspective on Society" International Migration Review 38:4 (2004), 1002.

${ }^{24}$ Valentina Mazzucato, "Bridging Boundaries with a Ttransnational Research Approach: A Simultaneous Matched Sample Methodology" in Muilti-sited Ethnography, ed. M.A Falzon (Farnham, MA: Ashgate, Forthcoming), 216.
} 
While Levitt and Schiller emphasize the participation of migrants in the lives of their homelands, I suggest that this participation is a two sided one; that is, homelands also extend their activities into the various diaspora. There are instances where relatives of migrants support them financially, religiously, socially or through other means from the homeland. Government officials from the homeland also extend their activities to fellow countrymen in the diasporas. During my data collection, I observed that although bereaved family members in South Florida perform post-death rituals in South Florida for relatives who died either in South Florida or in Ghana, they still have to send money for the funerals performed in Ghana. One of the key themes in this thesis is that religious praxis provides a congenial context for these forms of simultaneous participations of migrants in both worlds. I engaged these two understandings of simultaneity, especially in Chapters 2 and 4 in exploring how funeral rituals (in Ghana and the USA) enable Ghanaian migrants to participate in the lives of their kinsmen back in the homeland and vice versa.

\section{Literature Review: Religious Expressions in the New Africa Diaspora}

A growing body of writings explores forms of religious expressions among Africans in the new diaspora in the West. ${ }^{25}$ The bulk of these writings analyse the role of religion in the lives of African migrants in their quest for identity and adaptation in the institutionalized context. In From Africa to America: Religion and Adaptation among

\footnotetext{
25 Nida Worku, “African Religious Beliefs and Practices in Diaspora: An Ethnographic Observation of Activities at an Ethiopian Orthodox Christian Church in Los Angeles," in African Immigrant Religions; Afe Adogame, "From House Cells to Warehouse Churches? Christian Church Outreach Mission International in Translocal Contexts," in Travelling Spirits: Migrants, Markets and Mobilities, eds.Gertrud Huwelmeir \& Kristine Krause, (New York/London: Taylor \& Francis Group, 2010);

Biney, From Africa to America.
} 
Ghanaian Immigrants in New York (2011), Moses O. Biney analyses the role of religion in the lives of African migrants in their quest for identity and adaptation. Focusing specifically on the history and social location of the Ghanaian Presbyterian Church in New York, he demonstrates how the church plays a crucial role in the adaptation of migrants in New York. He notes that although most migrants face some form of discrimination, it is more intense with African migrants because of their visibility as dark-skinned minorities in the American ethnic mix. He notes "social discrimination for most Ghanaians is often high due to their dark skinned color just like any other African or Caribbean people." The author calls this "double jeopardy," where Ghanaian migrants are often discriminated against for economic and social reasons because they are black. ${ }^{26}$ These challenges aside, African migrants in general are faced with the greatest ordeal of how to order their lives and interact with persons and institutions in their new environment so as to attain their goals without losing the essence of who they are. ${ }^{27}$ The quest for identity, adaptation and maintaining ties with the migrants' homeland is what the Ghanaian Presbyterian Church in New York seeks to offer Ghanaian migrants. The church also provides economic, social as well as cultural supports to these migrants. This is done through the singing of church songs in the native languages of migrants and also through the traditional performance of social, cultural and religious activities or ceremonies of the migrants. ${ }^{28}$

\footnotetext{
${ }^{26}$ Biney. From Africa to America, 26.

${ }^{27}$ Biney, From Africa to America, 90.

${ }^{28}$ Biney, From Africa to America, 90.
} 
A similar assertion is made by Nida Worku in her work, "African Religious Beliefs and Practices in Diaspora: An Ethnographic Observation of Activities at an Ethiopian Orthodox Christian Church in Los Angeles." In the ethnography, Worku discusses the role that religious activities play in the trans-national identity-creation process among Ethiopian immigrants at the Virgin Mary's Ethiopian Orthodox Tewahedo Church in Los Angeles. Drawing on personal experiences of Ethiopian immigrants in Los Angeles, the author argues that the church "is more for social and cultural reasons than religious ones" in that it serves as the focal point of Ethiopian ethnic identity. An interviewee is reported as saying, "I had my son baptized here ... according to Ethiopian orthodox traditions ... we want our son to stay in touch with the Ethiopian side of his cultural roots." ${ }^{29}$ Like the Ghanaian migrants in the work of Biney, the Ethiopian migrants in this study regard the church as means of recreating their Ethiopian identity as well as well as a link in maintaining their Ethiopian homeland's orthodox values or traditions. The author concludes that "the church was a fulfilment of Ethiopian immigrants' dream of finding a spiritual home." ${ }^{30}$ The idea here is that the church has become an institution that links these migrants to their homeland.

An important gap in the emerging literature, which my thesis attempts to speak to is the lack of focus on religio-cultural practices that do not necessarily take place in formal religious contexts, yet play important roles in fostering a sense of ethnic identity and in linking communities to their homelands. These include the rites of passage African migrants in the West practice. The significance of my thesis rests on the light it sheds on

\footnotetext{
${ }^{29}$ Worku, "African Religious Beliefs and Practices in Diaspora," 211.

${ }^{30}$ Worku, "African Religious Beliefs," 211.
} 
how such informal religious practices perform roles akin to those that the formal religious traditions play in the lives of Ghanaians in the diaspora.

\section{Organization of Chapters}

Chapter 1 is the general introduction to the study. It includes my literature review, theoretical frameworks and description of data collection. Chapter 2 exposes readers to Ghanaian understandings of death, dying, the religious underpinnings of these ideas and how these inform funerals. Chapter 3 is a description of the United Ghanaians Association in South Florida. Here, the composition of the Association, location of members, its history, the migratory stories of members and the role of the Association in the lives of Ghanaian trans-migrants will be discussed. The next chapter provides an analysis of funerals in terms of how they function as community integrative symbols in the diaspora, contexts for producing and performing identity. The chapter also discusses how Ghanaian migrants participate in funerals in both the Ghanaian world and the diaspora. The final chapter is the general conclusion of the thesis. It ties together the themes that run through the thesis.

\section{The Study's Relevance}

Although historians of religion and other scholars recently have focused on the interconnectedness of religion, diaspora and migration, the bulk of the studies have concentrated on the religions of North America and the Americas, hardly ever dealing with the various new religious movements from Africa that have contributed to the diversification and richness of the United States. The emerging ones on religious movements from Africa however, to a large extent focus on formal religions, neglecting African religious practices that take place in settings not considered primarily religious. 
This study therefore adds to academic knowledge by demonstrating how African religious practices that take place in settings not considered primarily religious, such as funerals, play crucial roles in the lives of Ghanaian trans-migrants in South Florida.

In the next chapter, I discuss the Ghanaian understandings of death, dying, and the religious underpinnings of these ideas and how these inform Ghanaian funerals. 


\section{CHAPTER 2}

\section{CONTEXTUALIZING DEATH AND DYING IN THE GHANAIAN WORLDVIEW}

The objective of this chapter is to expose readers to Ghanaian understandings of death, dying, the religious underpinnings of these ideas and how these inform funerals. The discussion presented in the chapter also provides an important backdrop for understanding the importance of Ghanaian funerals as symbols of community integration and avenues for linking Ghanaian migrants in South Florida to the homeland, themes which will be discussed in detail in the later chapters of the study. The key theme discussed here is that in Ghana, funerals are venues for making important social contacts and community integration. Funerals are venues for making important social contact and community integration because it is a cultural expectation for a deceased's extended network of relations, including those living in the diaspora, in Europe and America, friends and acquaintances from far and near, to attend the funeral as the final show of love and respect for the dead who, in indigenous religious discourse, is journeying to the world of the dead. Another reason is that there is an emphasis on successful funerals in Ghana and this success is determined largely by the grandeur of the funeral and the large number of mourners who attend it. The grandeur of the funeral makes it necessary for all who know the dead to attend the funeral.

I also discuss the Ghanaian concepts of "good" and "bad" deaths and the emphasis on performing the "right" post-death rituals as a necessary condition not only for ensuring the deceased's smooth journey to the land of the ancestors but also, for opening doors for the blessings of the spirits to flow into the community of the living. I 
also argue that modernization and globalization have introduced changes to indigenous Ghanaian funeral rituals in modern times. Funerals have become a context for showing off the deceased's family's wealth and how globally connected it is (through family members living in far flung parts of the world). These are signs of the family's high social standing. Not only have Ghanaian trans-migrants in South Florida extended the funeral's role in integrating diasporic with non-diasporic communities because the families in Ghana consider the trans-migrants to be better off economically. Transmigrants are also pressured to contribute the bulk of the resources needed to stage a grand funeral in the homeland. Very often, migrants must also travel to participate in the funeral at home in order to show that the family has sons and daughters living in the West and thereby boost its social standing.

\section{Death in the Akan Worldview}

Since Ghana consists of different ethnicities and each ethnicity has a unique understanding of death, I offer a general discussion on the Ghanaian notion of death. Specifically, I focus on the worldview of the Akans, the largest ethnic group in Ghana. Another reason is that the Akans constitute the largest of the Ghanaian ethnic groups represented in the United Ghanaians Association of South Florida and all cultural activities including funerals are modeled after Akan traditions. Moreover, there is adequate documentation on the culture of the Akans, which according to Patrick Twumasi, has had a profound effect on the present cultural situation of Ghana. ${ }^{31}$

\footnotetext{
${ }^{31}$ Patrick A. Twumasi, Medical Systems in Ghana: A Study in Medical Sociology (Tema, GH: Ghana Publishing Corporation, 1975), 13.
} 
The Akan worldview, like other African worldviews, is divided into "two interpenetrating and inseparable, yet distinguishable parts, ${ }^{, 32}$ namely the worlds of spirits and humans. A central tenet of the belief in the worlds of the spirits and humans is the belief that the spirit world permeates the very existence of the Akan and "has deep roots in the lives of individuals." ${ }^{33}$ The belief that the spirit world "has deep roots in the lives of individuals' is seen in every aspect of Akan people; social, economic, political and health. The whole existence of the Akan and other Ghanaian ethnic groups derives its meaning from religion. And understandings of death cannot escape the influence of religious meanings. Akan understandings of a universe filled with a myriad of spirits, a category of beings known as the "living dead" who play a central role in the lives of the living and of the tripartite human being, inform their notions of death and dying and the post-death rituals associated with death. In what follows I will discuss these notions.

Akan people believe in a hierarchy of myriad spirits in the universe. Onyame, the Akan term for God, which implies the basic idea of Deity as understood in Christian and Islamic theologies, (God/Allah), is regarded as the head of this hierarchy in Akan religious discourse ${ }^{34}$ Onyame is attributed with the creation of the universe, does not have any cult, priests or priestesses, and does not deal directly with or interfere in the

32 Cyrill C. Okorocha, The Meaning of Religious Conversion in Africa: The Case of the Igbo of Nigeria (Aldershot, BF: Gower Publishing, 1987), 52.

${ }^{33}$ See the works of: John S. Mbiti, Introduction to African Religion. $2^{\text {nd }}$ ed. (Oxford: Heinemann Educational Publishers, 1975), 153; Patrick A. Twumasi, Medical Systems in Ghana: A Study in Medical Sociology (Tema, GH: Ghana Publishing Corporation, 1975), 38-39; Kofi Appiah-Kubi, Man Cures, God Heals: Religion and Medical Practice among the Akans of Ghana (New York: Friendship Press, 1981), 1-2; Olupona, "Introduction," 1.

34 Among the Akans, Onyame is a male. However, among the Ga ethnic group of Southern Ghana, Onyame is both male and female. The Gas refer to Onyame as Atta Naa Nyumo. Atta is title for a father while Naa is a title for a mother. The ethnic groups determine Onyme's gender. 
affairs of the universe, especially humankind. Rather, it is believed that Onyame created lesser divinities/gods/deities (abosom plural) to serve as intermediaries between him and humankind. ${ }^{35}$

These divinities have the power to mediate the needs of humans and are at the centre of priesthood and cults. Some of the gods are associated (not necessarily identified) with various aspects of nature, such as thunder, mountains, lakes rivers etc. Others relate to the traditional units of social structure. That is, they are patron deities of families, lineages, clans, ethnic groups and geographical settlements such as towns and traditional areas. Some are also linked with skills, vocations and professions, such as weaving or fishing, but their roles are not exclusive and one god may fall into a number of these various categories. ${ }^{36}$ The divinities/gods/deities mediate the needs of humans, offering them protection, healing and adjudicating cases supernaturally and punishing those at fault.

Apart from the gods, the ancestors (Nanaanom nsamanfo) form a very important aspect of the traditional Akan ontology. Ancestors are persons who have distinguished themselves in the society during their life time. Their distinction is based on either they died a natural death (that is in their sleep), at an old age, contributed positively towards the development of the community and most importantly had children (males in most cases) to continue their lineage. After their death, they are believed to still influence the

\footnotetext{
35 Divinities, deities, gods generally refer to the same concept. I use these terms interchangeably. See the works of, Birgit Meyer, Translating the Devil: Religion and Modernity among the Ewe in Ghan (Trenton: Africa World Press, 1999), 65; Elom Dovlo, "Report on Trokosi Institution," a Report submitted to International Needs in October 1995, 3.

${ }^{36}$ Dovlo, "Report on Trokosi," 3.
} 
lives of their descendents by: mediating their well-being within the spirit world; serving as the guides and guards of moral conduct; underpinning the social system of corporate identity and sustaining their lineage in general. It is this continuous relationship with the living that led John S. Mbiti to refer to ancestors as the "living-dead," making them the closest link that humans have with the spirit world. ${ }^{37}$ Ancestral cult is one of the strongholds within the Ghanaian worldview.

The principal function of the gods and ancestors in traditional belief is that they provide for human needs. They are also believed to provide protection from the various inimical powers that form part of the spiritual landscape of traditional belief. ${ }^{38}$ These powers include various evil spirits such as the power of witchcraft and sorcery. Both positive and negative powers are believed to manifest themselves in the world. Nature is also believed to reflect these powers and is not regarded as a mere physical substance. In most African traditional belief, nature is imbued with various forms of spiritual potency that humans must harness and relate to in peculiar ritual in order to find meaning in life.

It is believed that human beings, or what Pierre Bourdieu terms social agents, ${ }^{39}$ lie at the centre of this universe and are the main focus of these powers. People therefore seek harmonious relationships with these spirits to guarantee their well being. Accordingly, Asare Opoku notes "nothing can be well with men in society if good relations are not maintained between their fellow humans and the powers that control the

\footnotetext{
${ }^{37}$ Mbiti, Introduction, 107.

38 Meyer, Translating the Devil; Kwame Gyekye, An Essay on African Philosophical Thought: The Akan Conceptual Scheme. Revised ed. (Philadelphia: Temple University Press, 1995).

39 Terry Rey, Bourdieu on Religion: Imposing Faith and Legitimacy (London: Equinox Publishing Ltd., 2007), 39-40.
} 
universe. ${ }^{40}$ This relationship is principally facilitated through various rituals and ethical norms. ${ }^{41}$ Thus, for most Ghanaians and Akans in particular, the totality of humanity's existence, including economic, political, social and health components, is dependent upon the dictates or the influence of the spirits. The understanding of the "two inter-penetrating and inseparable, yet distinguishable parts”42 of the universe has influenced Ghanaians perception of the human body.

\section{The Tripartite Person}

As the person is the one who experiences death, Akan understandings of the person or the human being shed considerable light on the conceptualization of death and funeral rites. My discussion on the concept of the human body follows the questions Kwame Gyekye asked when discussing this concept among the Akans. He asked, "Is a person just the bag of flesh and bones that we see with our eyes, or is there something additional to the body that we do not see?" He indicates that, "the human body is highly symbolic." ${ }^{43}$ Among Akans, the human being, known as nipadua or nipa, is made up of the soul (okra), spirit (sunsum) and blood (mogya). According to Gyekye, the soul (okra) an intangible element, is the aspect of human being given by God (Onyame) as the bearer of his or her destiny (nkrabea). The spirit (sunsum), which is transmitted to a person from the father's semen, is another intangible part. The spirit accounts for one's intellectual and character

\footnotetext{
${ }^{40}$ Kofi Asare Opoku, West African Traditional Religion (Accra, GH: FEP International Private Limited, 1978), 49.

41 Dovlo, "Report on Trokosi," 3.

${ }^{42}$ Okorocha, The Meaning of Religious Conversion in Africa, 52.

${ }^{43}$ Kwame Gyekye, An Essay on African Philosophical Thought: The Akan Conceptual Scheme Revised ed. (Philadelphia: Temple University Press, 1995), 85.
} 
disposition. It is also that part of a human being which is opened to witchcraft attack. It is even linked with a person's ill health. The weaker the spirit, the more prone it is to witchcraft attacks and this can make a person sick. The blood (mogya) which is the physical component of a human being is received from the mother. The belief that an individual's blood is received from the mother explains why Akans are matrilineal. ${ }^{44}$ The soul, spirit and blood composition however, does not give a divided personality of man as divided into body-soul, spiritual-physical segments, but rather as a united personality, informing Akan understandings of death and dying and the post-death rituals.

\section{The Journey of Death}

Among Akan people, when a person falls seriously ill, relatives do not only watch by his bed side, but also try to find the cause of his illness, especially when relatives suspect a witchcraft attack, and also, in recent times, when his condition defies orthodox medicine. The eldest male member of the family (abusuapanyin) consults a traditional healer who is able to communicate with the spirit world and determine the causes of the illness through divination. If the sick person is unable to recover, the kinsmen then focus on the postdeath ritual (s) for the deceased.

Ghanaians in general, and Akans in particular, believe that "when a person dies, the body (nipadua) goes to the ground, 'to be food for ants,' the soul (okra) which is the breath of life returns to God; while the spirit (sunsum) returns to the ancestral world to join the ancestors. From that world the dead visit the living now and again." ${ }^{\circ 5}$ On the

\footnotetext{
${ }^{44}$ See: Gyekye, An Essay on African Philosophical Thought, 85-94; Opoku, West African, 95-151; Appiah- Kubi, Man Cures God Heals, 11-12; Twumasi, Medical Systems in Ghana, 19-20.

${ }^{45}$ See the works of Peter Sarpong, Ghana in Retrospect: Some Aspects of Ghanaian Culture, (AccraTema, GH: Ghana Publishing Corporation, 1974), 22-23; Michael Jindra \& Joel Noret, “African
} 
basis of this, death is not seen as the end of life but rather as a journey to the lands of the creator (Onyame), and the land of the ancestors (asamando). Peter Sarpong describes death as the "occasion when a deceased person sets out on a journey to the underworld or spirit world to which the ancestors have already gone." ${ }^{\prime 4}$ The understanding that death is a journey, to an extent, explains the practice of putting items such as money, food, clothes and water into the coffin before the dead are buried. These items are believed to sustain the deceased on the journey to the land of the ancestors (asamando). The understanding of death as a journey also informs the numerous expressions Akans use when someone dies. The death of an individual is usually not announced in plain words but rather, expressed in an idiomatic way such as, "he or she has joined the land of the ancestors," "he or she has embarked on the journey of no return," and "he or she has been called by the ancestors." The journey of owиo (death) is inevitable and inescapable; everyone will embark on it someday. The Akan symbol owuoatwedea (the ladder of death) and the proverb "owuo atwedea, obako nfu" (the ladder of death is not only climbed by one person) express this understanding.

Fig. 3 An Image of the Akan Symbol, owuoatwedea- the Ladder of Death.

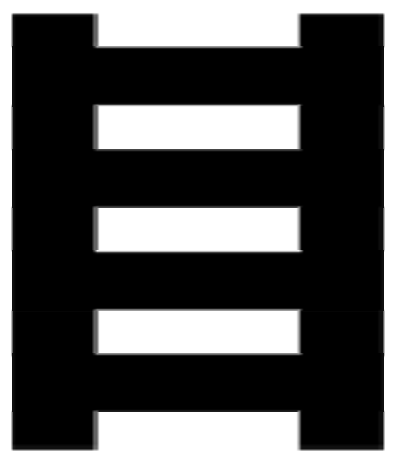

Funerals and Sociocultural Change: A Review of Momentous Transformation Across a Continent" in Funerals in Africa: Explorations of a Social Phenomenon, eds. Michael Jindra, \& Joel Noret, (New York/London: Berghahn Books, 2011), 183.

${ }^{46}$ Sarpong, Ghana in Retrospect, 22. 
However, emphasis is placed on "climbing the ladder of dead" in a good way. For this reason, Akan people have concepts of "good death" and "bad death." A "good death" (owиo pa) means dying in accordance with the standards of death set by the society. It usually includes: dying in ones' sleep; dying at an old age, normally above 70 years; giving birth to lots of children; and having contributed positively towards the development of one's community. The Akan saying, "He or she did not wake up from his or her sleep" only emphasizes the idea that "good deaths" are preferred to any other kind of death. The preference of "good death" to "bad death" is underpinned by the fact that a "good death" makes it easier for the deceased to transit from the land of the living to the land of the ancestors, continuing the harmonious relationship between the living and the dead and providing for the needs of the living. The understanding that there is harmonious relationship between the dead and the living gives rise to nkradea, a practice in which the living "convey" messages to the land of the dead or the ancestors through the deceased. For instance it is a common practice that during the post-death ritual, the living, while staring at the corpse, would say, "As you are going, tell so and so that they should remember us. We need medicine for such and such ailments." Nkradea is comparable to the common practice of the living asking a traveler going to a place where living relatives are to convey a message on their behalf. The practice of nkradea affirms the worldview that the dead still play an active role in the life of the living. Also, a "good death" usually does not require the living to perform complex post-death rituals needed in the case of a "bad death." 
On the other hand, a "bad death" (owuo boni) is that which occurred "outside" of the standards set by the society; it is the opposite of a "good death." It usually involves "shameful" death means such as through suicides, accidents, dreaded diseases, such as leprosy and in modern times HIV/AIDS, to die at a young age, and/ or to die childless. Peter Sarpong describes the sense of shame that comes with a "bad death" in the following words: "Nevertheless, no death is more shameful than a death brought about by such "unclean diseases" such as leprosy, epilepsy, or death at child-birth, or death of one alleged to be a witch. ${ }^{37}$ Within the traditional Akan worldview, deaths through suicide, accidents and dreadful diseases bring "shame" to the community and also, ritually pollute the community and the land of the ancestors. Suicide is shameful because life is Onyame (God-given), and he is the only one who can take it away. It is a taboo for the living to take his or her life, or the life of a fellow nipa. Such deaths require the performance of complex rituals before the living can "touch" the corpse (efunu). The ritual is to cleanse the community and anyone who comes in contact with the corpse (efunu). These criteria for "bad deaths" do not mean the Akans do not recognize that not all nipa will fulfill the same or similar destinies. That is, the Akans know that not everyone will bear children, die at an elderly age, or meet others of the "good death" criteria. However, because of the belief that one's spirit (sunsum) is opened to witchcraft attacks and is also the seat for spiritual causes of ill health, should one die at a young age, there is a tendency to suspect a witchcraft attack on the sunsum. ${ }^{48}$ Usually, through divinations, relatives of the deceased discover if the cause of the death is one's destiny (nkrabea) or otherwise.

\footnotetext{
47 Sarpong, Ghana in Retrospect, 27. Some of these diseases are being looked at differently now.

${ }^{48}$ See Sarpong, Ghana in Retrospect, 25.
} 
Unlike "good deaths," "bad deaths" require a complex ritual process since the deaths have polluted the living and also make it impossible for the dead to enter the land of the ancestors. Their non-admission into the land of the ancestors (asamando) leaves them "hanging between two worlds," the world of the living and the world of the dead. On the one hand, they are dead and therefore cannot "live" with the living. On the other hand, the cause of their deaths makes it impossible for them to enter the land of the ancestors (asamando). Such spirits are regarded as "wondering ghosts" (samantwentwen). Among the Akans and most ethnic groups in Ghana, such spirits are believed to cause havoc in society. They are responsible for disasters such as epidemics, rapid deaths in society, barrenness, drought, and low crop yields. Basically, the living try to avoid the havoc of "wondering ghosts" (samantwentwen). A way out of this predicament is for the living to perform elaborate and complex post-death rituals in order for the deceased to be accepted into the land of the ancestors.

One could argue that the journey of death places not only the dead, but also the social structure and the identity of the living at a threshold since the success of the deceased's journey to a large extent is dependent on the post rituals performed by the living. While it may seem that the living hasten to cut all ties with the newly dead, yet as soon as the same dead are on their way to become ancestors, the living nonetheless also want to communicate with them. In this regard death could be seen as something not feared but regarded with power and awe. ${ }^{49}$ This does not mean that the Akans regard death as a good thing; it has its negative connotations. Owuo destroys families, makes

\footnotetext{
49 Marleen de Witte, Long Live the Dead: Changing Funeral Celebrations in Asant, Ghana (Amsterdam, NL: Aksant Academic Publishers, 2001), 8.
} 
children orphans, and separates loved ones. This is depicted in the lyrics of a Ghanaian highlife singer, Nana Tuffour. The song, "owuo sei fie" (death destroys the home) has the lyrics, "owno sei fie owno atwedea wo wei sana baku nfu, owuo sei fie" translated as, "death destroys the house, everyone will climb the ladder of dead, death destroys the house." ${ }^{50}$ There are also common sayings such as, "death is wicked," "death deprives people of good things," "death leads to poverty" and "death leads to despair and hopelessness."

The emphasis placed on "proper rituals" as a way of facilitating the easy transfer of the dead to the land of the ancestors and avoiding the wrath of angry ghosts, the sense that a funeral is the last public act the dead will participate in with the living, the time and energies and other resources such as money to be expended in funerals, all call for the committed engagement of all members of the deceased's extended network of relatives. These demands also make funerals bring together kith and kin from far and near, making them very important community integrative symbols in Ghanaian culture. In the discussion that follows I offer an account of Akan post-mortem ritual process, demonstrating this involvement of entire communities. The discussion on Akan post mortem ritual will shed considerable light on reasons why Ghanaian migrants in South Florida pay respectful attention to the need to involve the entire community in funerals and why some migrants must travel back to the homeland to participate in funerals or at least send home money to pay for the cost of organizing them.

50 Translation mine. 


\section{Post-Mortem Rituals}

Customarily, Akan families inform members of a death immediately after it occurs. The reason for informing family members quickly is to facilitate the family's meeting and deciding on the necessary and befitting funeral rituals. Such meetings, called naawotwe $d i$, take place a week after the death. At the naawotwe di, relatives decide on the day for the burial, the type of coffin to use, and the type of food mourners will eat at the funeral, how the deceased should be dressed, and most importantly, the funeral cloth to use. Family members are also assigned specific tasks. The most important consideration of a bereaved family in planning a funeral is how to make the funeral a successful one. Success in a funeral is determined by how large the population of mourners are, how grand it is, the quality of the coffin, the high social standing of those who attend, and the good quality and large quantity of food and drink served to mourners. Great effort is expended in ensuring that funerals meet these standards.

Funerals are regarded as processes and not as events in Ghana. Depending on the status of the deceased (while living), and the nature of the death, funeral rituals can last up to a couple of days, weeks, months and even a year or more. Marleen de Witte notes this about Asante funerals in Ghana, "an average Asante funeral requires lot of time, effort, organisation and money. It is a long process, starting from the moment of death, with the last celebration after one year, incorporating several ceremonies and events." ${ }^{11}$ Announcing the Dead. Customarily, when a death occurs in a family, other family relatives of the dead must be informed. The eldest male member of the family, the abusuapanyin, is usually the first point of call. He then delegates members to inform

${ }^{51}$ de Witte, Long Live the Dead, 8. Asante is one of the sub-groups within the Akan ethnic group. 
other relatives of the death (owuo). It is only then, that friends of the deceased (efunu) and sympathizers of the family are informed of the death. It used to be that when modern modes of transportation were not available, delegates walked long distances to convey the message. However, with the advent of technology, such long walking distances are no longer in practice. The use of telephones, fax, electronic mails (emails), and other social media technologies have now become the common means of "announcing" deaths in families to relatives, including those living in far flung overseas locations. The period between the death until the announcement is made to a large extent is determined by the status of the deceased. In the case of a traditional ruler or a member of a royal family, it could take a year for a community to be told of the death of the ruler. For a traditional ruler, there is a belief that, at his or her death, the spirit world must not only "absorb" the corpse but also that the royal household must perform certain rituals before informing the community or the public of the death. ${ }^{52}$ In the case of a child's death however, usually only relatives are informed of the death.

In modern times, in Ghana, the print media and electronic media, especially the radio, television and internet- the main media of "announcing" deaths in families- have made it easier for bereaved families to reach as many people as possible. Most FM and television stations in Ghana have slots for funeral announcements as part of their daily broadcasts. The funeral announcements include the family name of the deceased, the funeral date, surviving children and spouse (if any), surviving parents and siblings (if any).

52 This information is based on my interaction with my 92 year old maternal grandmother and also, my participations in the post death ritual of a late chief of Agona Swedru, a town in the Central Region of Ghana. 
Fig. 4 Some Ghanaian Funeral Posters. On the right is the Funeral Poster of Ghana's late President, John Evans Atta Mills who died in 2012.

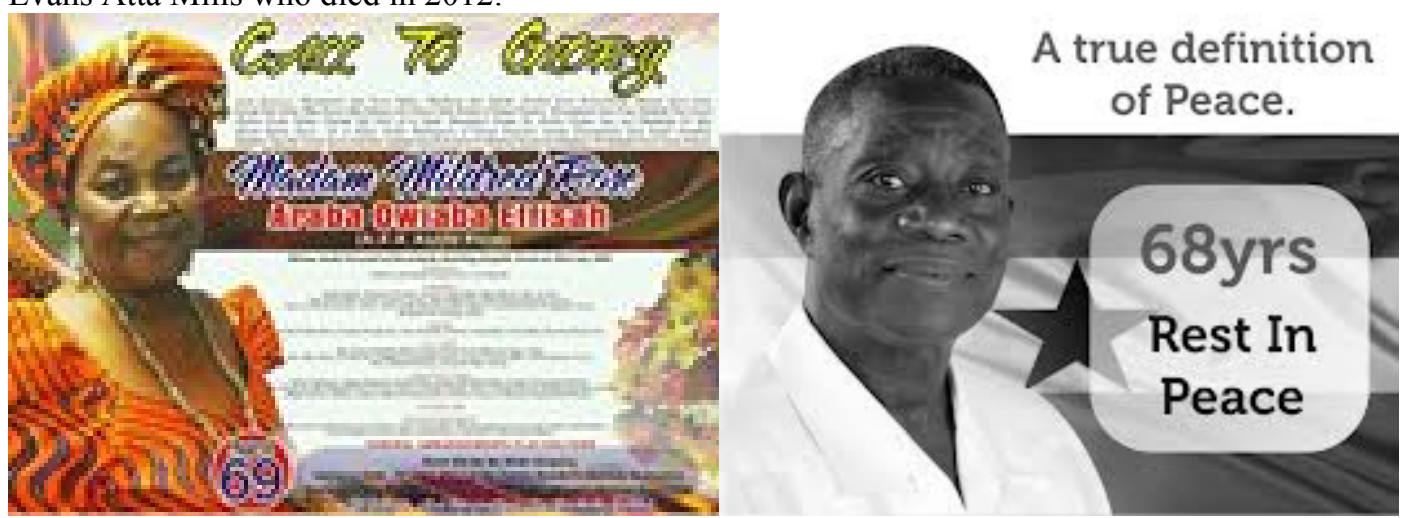

Funeral Cloth. Even the clothes worn by mourners play important roles in fostering unity among groups of the deceased's mourners. Ghanaian funeral cloths are highly symbolic. The designs of the funeral cloth, the name of the design, and the color tell the age, gender and status of the deceased and also indicate the emotions or the affections of the living towards the dead. The bereaved family decides on the type of funeral cloth the family members will wear for the funeral, and it is the custom that sympathizers will try as much as possible to go with what a family decides. Clothes colored black, white and black, deep or light brown (at times with a black pattern or design), and red (at times with a black pattern or design) or a combination of red and black, are usually used at funerals. Although the colors black or red or a combination of both colors and brown are worn for the funerals of the elderly, they can also be worn to any funeral regardless of the age and status of the deceased. However, the status and gender of the deceased are differentiated based on the names and designs of the cloth style. For instance, a funeral cloth called "Mother, your death is painful" (Ena wuwuo eye ya) cannot be worn to the funeral of a male or a child. It is worn when a mother dies. In Ghanaian culture the colors black, red or brown symbolize deep sorrow. People wear cloths of these colors especially when the 
deceased is young, to convey their profound sense of sorrow for a young person whose life has been cut short by death. It is said of such a person that he or she did not live to fulfill his or her destiny (nkrabea).

Fig. 5: A Picture of Mourners in Black and Red Funeral Cloths

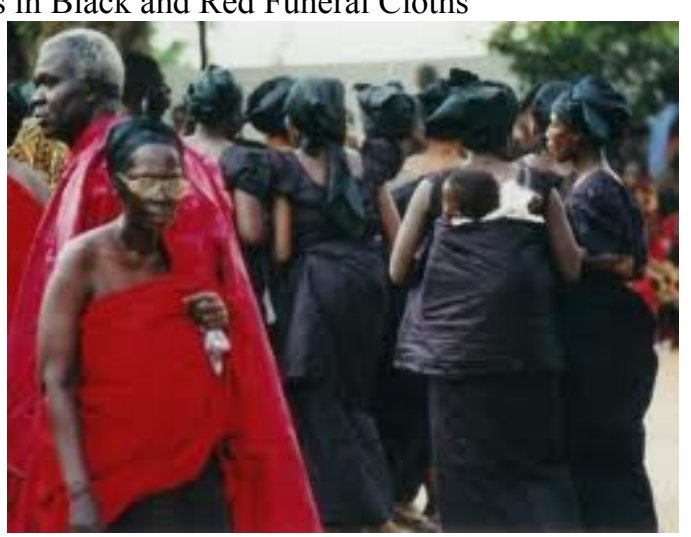

The colors white or a white with black pattern or design are usually worn to funerals of the elderly. Symbolizing joy in Ghanaian culture, these colors convey a mood of celebration. Although funerals are sad moments because a member of the living community is departing, the bereaved families and sympathizers take consolation in the fact that the deceased died at an old age, fulfilling his or her destiny (nkrabea). Such a person will be received warmly and will rest peacefully in the land of the ancestors (asamando), having fulfilled his or her God-given tasks on earth. It is considered inappropriate to wear a white cloth to the funeral of a young person.

Aside from wearing clothes in colors that convey cultural meanings and emotions during funerals, there are clothing styles that speak to how mourners are feeling or what they think about the death. Some common styles of funeral cloths that expresses emotions and thoughts of the bereaved include, "It is finished" (Se Asa), "Father's Death" (Egya wuo), "Death is wicked" (Owuo tirimu ye din), "Death destroys the home" (Owuo sei 
fie)," "I am now an orphan" (ma ye egyanka) and "Something dreadful has befallen me" (Adi ato meni).

Fig. 6: A Mourner in a White Funeral Cloth with Black Pattern or Design

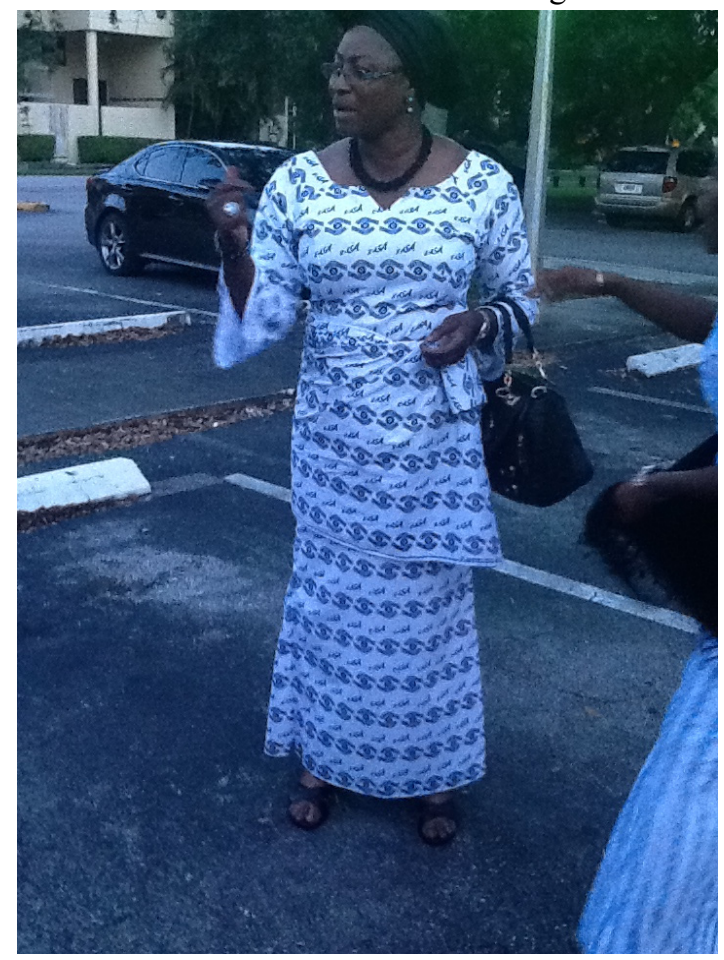

With the advent of technology, some of the funeral cloths have the image of the deceased imprinted on them.

Fig. 7: Image of the Head of the late President of Ghana, Atta Mills, printed on the Cloth for his Funeral

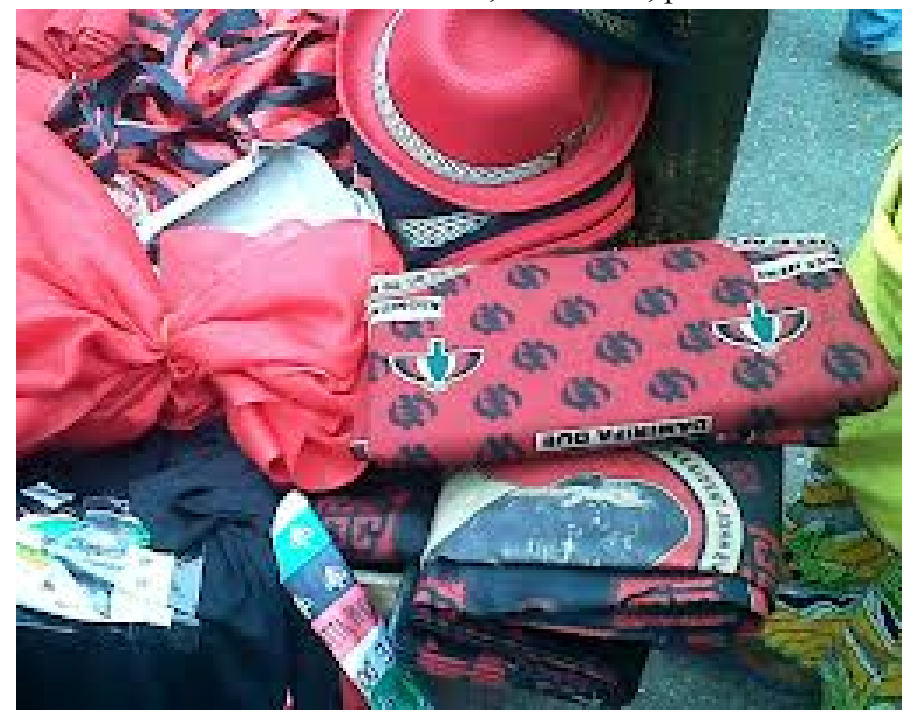


Sometimes, groups of the deceased's friends such as workmates, classmates, home town friends, and others decide to attend the funeral dressed in a particular cloth style or color. My reason for discussing clothing, color, and style symbolisms in Ghanaian funerals is first to demonstrate how very colorful Ghanaians funerals are. More importantly, I want to argue that these different colors and styles also function as identity symbols, fostering a sense of togetherness or oneness among groups of mourners clothed in attire of the same style or color. Through funeral colors and styles worn, funerals integrate groups of mourners.

While there are other aspects of Ghanaian or Akan funerals I could discuss, my interest in this chapter is mostly in those aspects of funeral that cement the solidarity of groups. Aside from the aspects I have discussed above, others, such as the burial, which is witnessed by all mourners, many of whom throw petals of flowers on the coffin as it is lowered into the tomb, the shared wailing that accompanies this action, the communal meal that often follows the burial of the dead, the distribution of insignias of the dead such as his or her photos, of pens, mugs or other items bearing his or her name, generates togetherness among mourners. The sense conveyed at funerals among mourners is one of "we are one people today, our divided loyalties are suspended, we have come together to bid goodbye to our beloved who is crossing over to the other side." As I intend to show in the chapters that follow, it is this aspect of funerals that lends it easily to usage by Ghanaian migrants in South Florida as an important cultural symbol of community integration. In other words, when migrants from Ghana to South Florida saw the need to come together as one group, the funeral seemed a handy cultural process. 


\section{The Influence of Western Modernity, Globalization and Funerals and the Involvement of Ghanaians in the Diaspora}

The process of globalization, the journeying of Ghanaians to overseas countries in the West to live and work, and the growing influence of Western lifestyles and formats in Ghana are affecting funerals in ways that have made them very costly processes. This is an important factor that has made it necessary for Ghanaian migrants to be more actively involved in funerals at home. Modelled after Western practices introduced to Ghana by "been tos" or Ghanaians who live and work in the West, Ghanaian funerals are now in the hands of "professional organizers," with very little role played by the members in the family. ${ }^{53}$

A funeral industry has emerged in Ghana since the late 1990s with a number of professionals controlling the various aspects. There are funeral homes that take care of the preparation of the body and sometimes the purchase of the coffin. There are pall bearer companies that specialize in the conveying of the body of the dead from the city to the village and from the church to the cemetery for burial. There are caterers who specialize in cooking and serving the multitudes that show up to mourn the dead. All of these professionals charge fees for their services. For instance, when my grandfather died in 2011, the family employed the service of a "professional corpse dresser" on Friday. No family member saw or supervised what the "professional corpse dresser" did with my grandfather's corpse, until he was laid in state on Saturday. In the past this was the

\footnotetext{
${ }^{53}$ Sjaak van der Geest, "Between Death and Funeral: Mortuaries and the Exploitation of Liminality in Kwahu, Ghana." Africa 76: 4, 2006, 486.
} 
family's responsibility. These new developments have made funerals in Ghana very expensive. The average cost of a funeral in Ghana is about 20,000 US dollars.

More important funerals are becoming contexts for families to show off their wealth and status in Ghanaian society. The higher the reputation of the funeral home a family uses or the catering company hired to cook for and serve mourners, or the pall bearer services used, the greater the social respect garnered by the bereaved family. Furthermore, in contemporary Ghana, where travelling to overseas countries to pursue an education or to live and work and send foreign money home is viewed as the way to go for the youth seeking upward mobility, the funeral has become a stage where families showcase how many of their members live abroad and how globally connected they are. The signs of this global connectedness include the number of family members who travel home from Western countries to attend the funeral, demonstrating all kinds of Western mannerism (such as ways of speaking English, dressing, the kinds of vehicles they drive in), the amount of foreign money that flows in to help pay for the funeral, the foreignness of the foods and drink consumed by mourners at the funeral.

In fact, funeral announcements emphasize specifically where in the world the surviving relatives live and work. On April 4, 2013, as part of the funeral announcements on Peace FM, one of the local FM stations in Ghana, the presenter indicated, "The family of ... regret to announce that Nana Pedu the second, chief of Abura Kwanta in the Central Region, has gone to the village. He was succeeded by.... residing in Switzerland, New Jersey ..." In another funeral announcement, the presenter said, "We regret to announce that the Head of News, Mr. ...son of ....passed away. The funeral service will take place at the International Central Gospel Church ... His sister ... lives in the United States ... and 
other sister.... works with EcoBank and Ghana Commercial Bank. His mother.... used to work with Ghana Commercial Bank ..." ${ }^{, 54}$

Where in the world the surviving relatives of the dead live and work is an important index of the funeral's success. Some Ghanaian sympathizers attend funerals based on the number of surviving members living abroad or working in prominent companies in Ghana. Their sense is that the more relatives or children abroad, the grander or better the funeral would be. It will be an "abroad funeral" (abrokyire ayie) in Ghana. To demonstrate affluence some families may serve their guests with beer and wine from America or Canada during the meal that normally follows the burial. Presumably these were "sent down" from relatives living in these parts of the world, a crucial sign of the family's global extensions. These new developments put a good deal of pressure on Ghanaian migrants to be actively involved in funerals at home. They must send money and other items, such as alcoholic drinks for the funeral, or must travel home to participate in person. This affirms Valentina Mazzucatos's assertion that funerals are becoming multi-sited events as migrants from developing countries play important roles in the organization, financing and practice of funeral ceremonies in their home countries. $^{55}$

\section{Conclusion}

The point of this discussion is to show how notions about death influence the place of funerals in Ghanaian culture, emphasizing the ways in which funerals integrate the persons, whole communities and circles of friends the deceased was involved in while

\footnotetext{
${ }^{54}$ The announcements were made in Twi one of the Akan languages. Translation mine.

55 Mazzucato, "Transnational Migration," 1047.
} 
alive. Although it may seem that Ghanaian indigenous notions about death and postdeath rituals are being challenged by a growing sense of individualism among Ghanaians, as well as by urbanization, Christianity and migration, funerals continue to play this integrative role. I have also shown how Ghanaians, and for that matter, Akan postmortem practices have rather become an open field of interaction where people combine local and globalized ideas. The perceptions about relatives living in the diaspora have made the cost of burying the dead very high and this has necessitated the active engagement of family members in the diaspora.

As I will show in the chapters that follow, in paying respectful attention to funerals in South Florida, Ghanaian migrants show an awareness of how important this cultural symbol is as glue for the community. Also Ghanaian migrants in South Florida, like others in different parts of the world, need to participate in funerals at home to help offset their high cost and also to demonstrate the social standing of their families as units with "children all over the world." As I argue in the chapters that follow, playing this role enables migrants to participate in the lives of their kith and kin in their homeland. The next chapter looks at the lives of Ghanaians in South Florida. 


\section{CHAPTER 3}

\section{UNITED GHANAIANS ASSOCIATION OF SOUTH FLORIDA}

In this chapter I provide a description of the United Ghanaians Association of South Florida (henceforth referred to as UGASF), which this study is about. Here, the history of the Association, its composition, the geographical locations of members in South Florida, their migratory stories, and the Association's role in the lives of Ghanaian transmigrants will be discussed. I discuss the "push" and "pull" factors that explain the Ghanaian presence in abrokyire, the Ghanaian way of describing far flung places on the globe, and specifically to America. A discussion of the "push" and "pull" factors will shed considerable light on the factors that motivated the creation of UGASF and the role it plays in the lives of Ghanaian trans-migrants in South Florida.

\section{The Association}

The United Ghanaians Association of South Florida (UGASF) is a 501 (c) (3) non-profit association incorporated in 1993 in Fort Lauderdale, with regular membership approximating about forty adults (mid twenties and above). About $75 \%$ of the members are women, 20\% men and 5\% teenage members. Occasionally some members come to meetings with their minors who are not really regarded as members of the Association, but who participate in the Association's activities such as poetry recitals, and/or Ghanaian cultural events such as drumming and dance performances. Although the membership of the Association consists of all the ethnic groups in Ghana, a large percentage of the members are from the Akan ethnic group, the largest ethnic group in Ghana, which also has the strongest presence in the USA. All the same, the Association's 
organizational structure does not reflect Akan culture; the various cultures of all the Ghanaian ethnic groups are represented in how the Association is organized. However, because of the Akan predominance, there is the tendency for the Akan culture to dominate most of the activities, sometimes to the chagrin of some members who are not Akan. For instance, the Association's emblem, Nkonsonkonson (chain link) is an Akan symbol symbolizing strength in unity, depicting the need for the members to unite.

Fig. 8 The Akan Nkonsonkonson (chain link) Symbol, the Emblem of the Association ${ }^{56}$

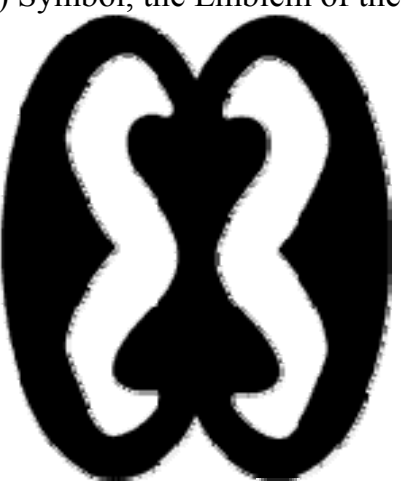

Also, I observed that after the usual monthly meetings or during social and cultural events, such as picnics or Ghanaian cultural displays, the predominant Ghanaian language spoken is $T w i{ }^{57}$ The queen mother of the Association models her roles after those of the traditional Akan queen mother in Ghana. Finally, most of the pictures on the Association's webpage are depictions of Akan culture, even though some cultural expressions and symbols of other Ghanaian ethnic groups can also be found there.

\footnotetext{
56 "West African Wisdom: Adinkra Symbols \& Meanings," http://www.adinkra.org/htmls/adinkra/nkon.htm [accessed, November 20, 2013].

57 Twi is the most common language spoken among members of the Akan ethnic group. The role of the queen mother will be discussed in the subsequent pages.
} 
Fig. 9 A picture of some members (moframofra and sankofa groups) performing the Akan Adowa dance. This picture is displayed at the Association's webpage

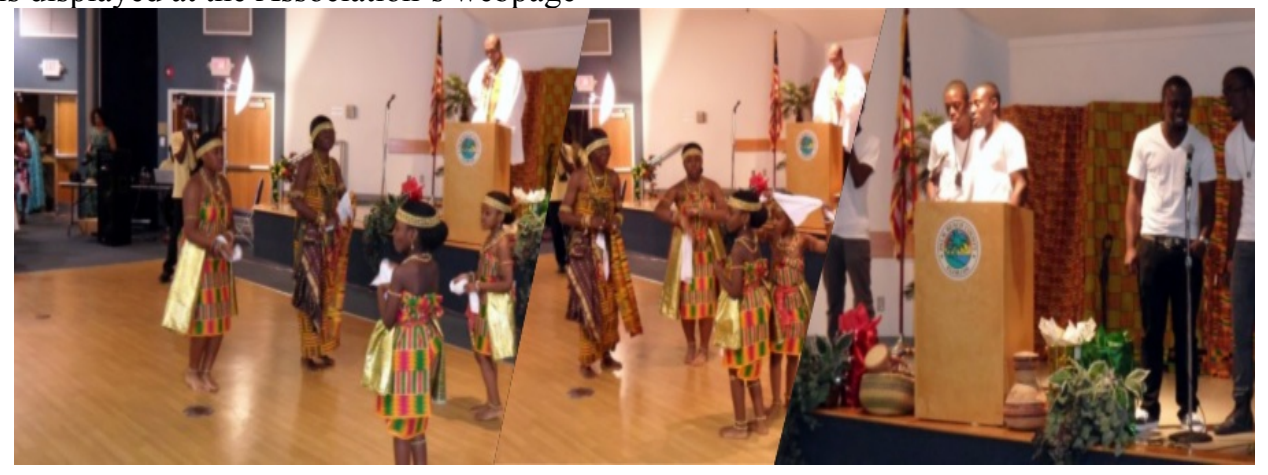

The Association meets the first Saturday of every month from 7 p.m. to 9 p.m. at Fort Lauderdale, located in Broward County. The monthly meetings are times for, but not limited to, planning events the Association wants to organize, raising concerns of members, discussing social, work and health-related issues. The reasons for choosing Fort Lauderdale as the meeting place include the fact that most of the members reside in Fort Lauderdale and also, the Association started in Fort Lauderdale, at the funeral of the mother-in-law of the late Cliff Lartey, a past member. The Association does not have a permanent place of meeting yet, a situation the Association president described as "the most challenging situation confronting the Association at the moment." "We keep moving from one place to the other" 58 he added, his face puckered with concern. He explained how the Association was contemplating getting a permanent place which members can call "our own."At the time of the research members met at the Broward County Library in Fort Lauderdale, for the meetings.

58 Omane, interviewed July 13, 2013. 
Fig. 10 Front View of the Broward County Library where the Association met at the time of the Research
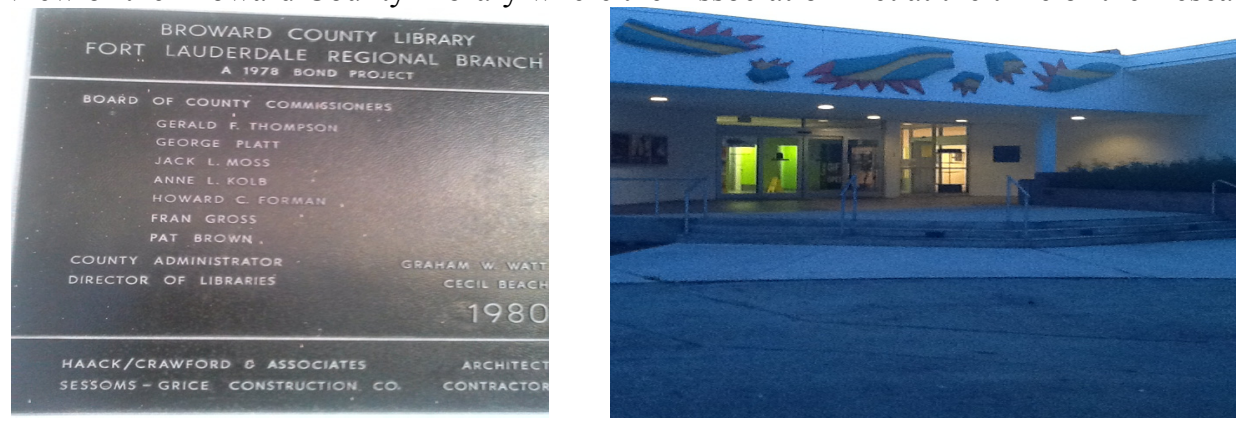

The organizational structure of the Association is hierarchical, with officers occupying the top position and ordinary members at the base. The highest office is that of the president, followed by the vice president (henceforth referred to as VP), the queen mother (Obahenema, the Akan word for a queen mother), the public relations officer (henceforth referred to as PRO), treasurer and the secretary, and also other committees (welfare committee, organizing committee and finance committee) and finally the council of elders. There is also the moframofra (children) and the sankofa (reclaiming the traditions of the past) groups. ${ }^{59}$ The president presides over all Association meetings, and also, all major issues are referred to him before final decisions are made. The VP assists the president in the daily administration of the Association. He acts in the absence of the president. The queen mother, who must be of Ghanaian descent or a naturalized Ghanaian, functions as a queen mother in Akan society, playing "roles the president cannot perform and also serves as the cultural ambassador of the Association." 60 For instance, during the performance of cultural displays, the president does not play any major role; the queen mother is given the "highest seat" and presides over the ceremony.

\footnotetext{
59 In this chapter, my emphasis is on the executive officers. The moframofra and the sankofa groups are discussed in Chapter 4.

${ }^{60}$ Omane, interviewed July 13, 2013.
} 
Also, like queen mothers in Ghanaian culture, she is regarded as a repository of traditional knowledge and a custodian of tradition and highly respected. The PRO has the responsibility of checking on the well-being of members periodically and bringing to the attention of the Association the situation of members going through crises. He is also responsible for conveying information on the group's activities to members, either through the internet, emails, or by calling them on the phone. The treasurer keeps records of the finances of the Association while the secretary keeps records of administrative works. The secretary is responsible for making announcements during meetings.

Interestingly, while the Association has created space for a queen mother in its organizational structure, the place of a chief (Nana Akan word for a chief) was not clearly defined in the organizational structure, even though chiefs, as I observed, play a crucial role in the Association. Recognizing this, the Association has amended its constitution and created a space for "Royal House of Chiefs and Queens" which defines the roles of Chiefs and queen mothers. Clearly, there are two systems of governance operating in tandem in the Association: the Western, and the traditional governance systems. There are the executive officers (the president, VP, PRO, treasurer, secretary) on the one hand, and also the traditional system represented by the Queen mother and the chief on the other hand. This seems to be a replica of Ghanaian modes of governing, in which modern/Western and traditional ways of governing operate in tandem.

\section{How the Association Originated}

Although there are varied accounts regarding how this Association originated, the consensus among members is that the death of a Ghanaian migrant prompted its beginning in 1992. The death of the mother-in-law of a Ghanaian migrant, Cliff Lartey 
(now deceased) in 1992 at Fort Lauderdale, and the high cost incurred in transporting the mother-in-law's body to Ghana and the subsequent funeral in Fort Lauderdale, South Florida, prompted the Ghanaian community in South Florida to form an association. Among other things, the Association was to "help cover the cost of funerals, and provide emotional support for the bereaved members." ${ }^{\prime 11}$ This socio-economic cushioning and support was deemed to be necessary in light of the high cost of funerary rituals both in the host country, America, and the homeland, Ghana, and the isolated lives Ghanaians live as migrants in South Florida. The fact that it was a funeral that occasioned the beginning of the Association underscores the crucial role of funerals as a symbol of this community's integration. A bereaved member's dead relative does not have to have been living in South Florida for him or her to receive support from the Association. The support also extends to the funerals of dead relatives back in the homeland. Thus, in the context of funerals, the Association also participates in the lives of family members back in the homeland. In the funeral rituals I participated in on June 15, 2013, although the death took place in Ghana, a ritual was held here to support both the relatives of the deceased living and working in South Florida and also those in Ghana. Monetary contributions from members of the Association were to help cover the cost of the air fare for relatives of the deceased in South Florida who were travelling to Ghana, and also, part of the funeral costs both in South Florida and Ghana.

Economically, the Association supports itself mainly through the monthly dues members pay and also from donations from some of the members. As of 2013, when I began the research, members paid $\$ 10$ as monthly dues. This amount has since been

61 "United Ghanaians Association of South Florida," http://www.ghanasouthflorida.org, [accessed, May 3 2013]. 
increased to $\$ 20$ and members are also required to contribute $\$ 20$ towards funerals and other social events aside from the monthly dues. Out of this, the Association pays the rent for their current meeting place; makes a $\$ 200$ funeral donation to bereaved families ${ }^{62}$ whenever there is death, and pays for the cost of organizing occasional social events.

Fig. 11 The president and the vice president of the Association making a Funeral Donation to a Bereaved Member in South Florida

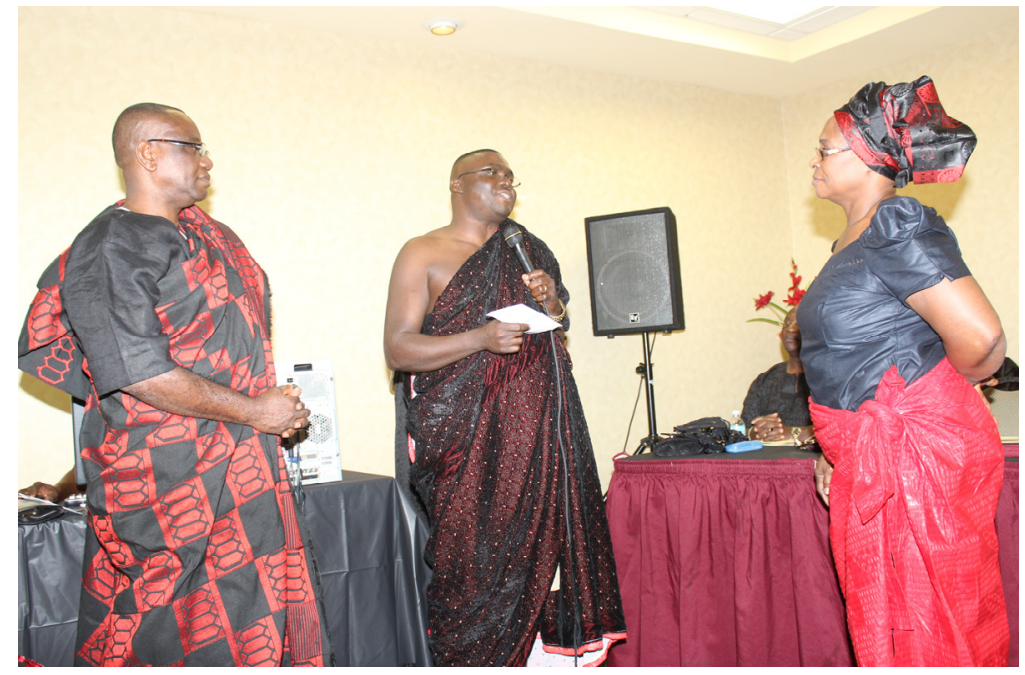

Because this money is not always enough to "deal with all the financial needs of the Association, ${ }^{, 63}$ members are encouraged to donate to the Association any little amount they can. For instance, during a picnic organized to mark Ghana's " $53^{\text {rd }}$ Republic Day Anniversary" at Amelia Earhart Park on July, 13, 2013, some members contributed \$50\$100. Others contributed fish, meat, steak, and soft drinks among others for a barbecue.

Over the years, the Association has extended its aim from cushioning or supporting bereaved members to the promotion of "the well-being and social prosperity of Ghanaians, fostering the unity and strength of South Floridian Ghanaians as a group, celebrating the group's cultural diversity in South Florida, and organize and execute [sic]

\footnotetext{
${ }^{62}$ The funeral donation has been increased to a $\$ 1000.00$ as at January 2014 .

${ }^{63}$ Omane, interviewed July 13, 2013.
} 
with pride, dedication and national dignity events such as traditional and cultural displays that portrays Ghana's rich culture."64

Fig. 12 Symbolic gathering of Ghanaian Traditional Rulers and Ritual Specialists dressed in Ghanaian Royal Regalia in South Florida. This picture displays the Ghanaian "cultural" diversity in South Florida. The image of the women in a smock with a gun in hand is a combination of Northern and Southern Ghana cultures

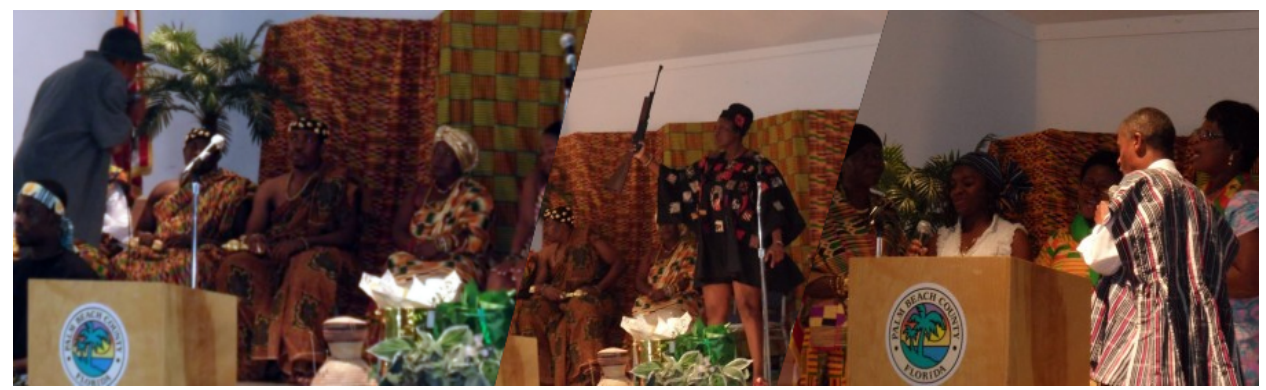

In the discussion that follows I offer an account of the migratory experiences of Ghanaian trans-migrants in the South Florida, particularly members in the Association. The goal of the discussion is to show how their experiences as African migrants in South Florida are linked with their motivations for creating an association, using funerals as an important cultural context for rallying together.

\section{Abrokyire / America}

Abrokyire is the Twi word used generally to refer to overseas countries especially Western counties- the United Kingdom, the United States of America, France, and Germany, among others. These places are also referred to as obronikrom (land of the Whiteman). For Ghanaians, America seems to have a more privileged status as the abrokyire country to be in. This is due to the sense of glamour and glitter Ghanaian people associate with life in America. Ghanaians have "fanciful" images of life in the USA. They view it as a land of opportunity and a greener pasture: where poverty has no

\footnotetext{
64 "United Ghanaians Association of South Florida," http://www.ghanasouthflorida.org, [accessed, May 3,
} 2013]. 
place in the lives of the people. Thus the mindset of most Ghanaians is that to be in America is to be in the real abrokyire. So, when in a conversation one indicates, often in a tone of pride, that his or her relative is "in America, abrokyire," the normal response is “eeh in America!" which conveys a sense of envy.

In this thesis, I use abrokyire in two ways; to refer to Western countries and nonWestern countries. Whenever I use the word, I will indicate which country in particular I am referring to.

\section{Memoirs of Our Departing and Our Transit}

The Ansah family, one of the families in the Association, introduced me to Uncle Ampewu (henceforth referred to as Uncle.) ${ }^{65}$ Uncle is in his late sixties and lives in Fort Lauderdale with his family; his wife and two boys. Although he was not very regular at the Association meetings at the time of the research in 2013 , he is very vocal and contributes to discussions whenever he comes. He is also regarded to be the abusuapanin (elderly male member or person) of the Association, a role that requires his active participation in the group's deliberations. ${ }^{66}$ Before interviewing Uncle, I had contacted him at one time to find out whether he knew about any impending funeral in the Association. "Of course I do. I am the abusuapanin; the funeral is 'on my shoulders.' They cannot perform the funeral without me," Uncle shot back even before I completed my question, emphasizing his crucial role as abusuapanin in the Association and in the

\footnotetext{
65 The Ansah family is discussed in Chapter 1.

66 His title is modelled after the Ghanaian understanding of abusuapanyin discussed in chapter two. He presides over all major decisions related to Ghanaian cultures in South Florida. Thus, no traditional event, such as funeral celebrations, take place without his knowledge.
} 
performance of such important rituals. During the funeral which came on a few weeks later, Uncle was literally the hub around which all activities took place.

My interchange with Uncle was through Skype, while he was at home. On several occasions he had to get up from the computer to attend to his sons or wife and this interrupted the smooth flow of our conversations. My inquiry into his involvements with the Association led to his account of the life struggles in Ghana that prompted his departure to an abrokyire land and finally to America. "Hmmm!!" he sighed before starting into the story. "I come from Breman Asikuma in the Central Region. After my secondary school [Senior High] in the 70s close to the 80s I moved to Liberia to seek for greener pasture." Why Liberia? I quizzed. He replied, "You know it was around that time where there was economic crisis in Ghana; the first military coup in Ghana. Everybody was fleeing to either Agege (Nigeria) or Liberia or other places for greener pasture."

After a brief detour, during which we both joked about how his narrative had to be "to the point" because I was taping it, Uncle concluded, describing how hardships in Liberia pushed him to seize a once-in-a-lifetime opportunity to come to America.

In Liberia, things were a bit tough. It was very difficult to survive. You know, Liberia is almost like Ghana, things are not that rosy. I really needed to go elsewhere, where I could make it. I did not want to go back to Ghana with nothing. I met some Ghanaians in Liberia in a similar situation. We decided to come to the U.S. when we got the chance. You know how everybody wants to go to the U.S., America. This is my story ooh (emphasis). This is what brought me to America and how I found myself in South Florida.

My interview with Mr. Ansah (henceforth referred to as Nana) echoed a similar theme. Nana is a chief from Elmina, a coastal village in the Central Region of Ghana. He is in his early seventies, retired and lives in Miami with the family; his wife and two children, 
Ama and Kojo. Like Uncle, Nana fled from Ghana's lingering economic depression and headed for oil-rich Nigeria (Agege) in the 1980s. Unlike Uncle, Nana explained that he did not travel to Agege to seek for a greener pasture but "just to be away for a while from the troubles and pressure I was experiencing at time. As a traditional ruler, I cannot leave my people. ${ }^{\prime 67}$ Nana returned to Ghana after a year. Five years after his return to his village from Agege, an old friend residing in Georgia invited him to America. He recounts how difficult it was getting a job in Georgia. At one time, his friend remarked how Nana had become a "financial burden" to him. He stayed with the friend for almost a year before relocating to South Florida to look for work. He later invited his wife and children to join him in South Florida.

Another respondent whose story shed light on how the harsh realities of life in Ghana pushed Ghanaian migrants to seek greener pastures in the United States is My Kupim, a father of four in his early forties. He works with one of the harbour companies in Miami and lives in Miami Gardens with his two daughters and one of his sons. From my first encounter with Mr. Kupim in February 2013 at Christian Restoration Ministries International at Miami Gardens we hit it off. "You are my daughter," he exclaimed when I (the researcher) mentioned my father's name, before he went on to describe in detail how well he knew my father. This encounter with Mr. Kupim was before I began the research for this study. Occasionally he would invite me to spend weekends with his family in Miami Gardens. "I did not have any plans of travelling, even though life was difficult as a teenager. My travelling happened by chance," Mr Kupim explained before

67 Nana, interviewed November 3, 2013. 
starting into an intriguing account of how difficult situations in Ghana forced him to come to America as a stowaway on a ship:

"I did not have any plans of travelling. Even though life was difficult as a teenager, I had no intention of travelling. My travelling was a coincidence... It was an opportunity I did not want to miss." This is what he said regarding how and why he left Ghana, "Hmmm!! you will not believe it, did you know I left Ghana in a ship without any footwear?" I laughed when he said this, but he appeared bothered by my laughter. He continued, "It is funny, right, but it is true. I did not even have a visa. I think God had a hand in my travelling."

That time I was working at Takoradi Harbor as an errand boy. I did all kinds of odd jobs. But the life was hard. Then one day I sneaked into one of the ships bounded for one of those countries... I don't even remember which country. It was one of my friends who talked me into this. They too joined me. I had no money, no visa. I did not even have shoes on. When the ship got to Egypt, one of the crew members discovered us. But by the Grace of God, the captain knew us as hard-working boys and said he could use our help on the ship. So we were in Egypt.

Did he pay or feed you? I interrupted. No" he responded smiling. He paused as if he was reminiscing on his ordeal, shook his head and continued the account:

No, he did not. We had to fend for ourselves. It was really difficult. None of us had money. We practically had to run errands for some of the crew members and as payment, they gave us the leftovers of their foods. Fortunately or unfortunately, the captain had to travel to the US and took me with him. Although I did not have a visa, the captain was able to smuggle me into the US. After spending three days in Maryland, he asked me whether I wanted to go back to Ghana. I said no. Even though I did not have any money or know anybody in Maryland, I knew I could make it in America. So he left me in Maryland and returned to Egypt. I struggled my way through life for some time before getting in touch with an old schoolmate here in Florida. He invited me over and allowed me to stay with him. He even helped me get a job and a place of my own. So that's how I came to live here. Later I sent for my children." 
For migrants like Uncle, Nana and Mr. Kupim, what "pushed" them out of Ghana was the political chaos and depression in Ghana in the early 80s. Before coming to the United States, they had sojourned in one of two other abrokyire countries. I found this pattern of migration in the accounts of most of my respondents. Viewing America through the Ghanaian cultural lens as a land of opportunities and greener pasture, they saw it as their ultimate destination and have made it their second home. The quest to find work, live the American dream, and send remittances to relatives in the homeland would define their lives in their newly adopted home of America.

\section{Life in America: Living in South Florida}

Their settling in South Florida, both initially and now, had not been without challenges. Some of my respondents spoke at length about these challenges tacitly and some-times, directly, providing clues to why they felt they needed an association.

Uncle, who has been in South Florida for over 15 years, shared his frustrations settling in to the life here with me. "First was the language," he began before a detailed description of how language was a handicap to him in his early days as a migrant in South Florida.

It was very difficult to express myself because people always said they could not understand what I was saying and that really frustrated me. At one time, someone just stopped listening to me while I was still talking. I felt really insulted and annoyed. This was worst with the Hispanics. 
I interrupted with my own experience of talking with an accent at Florida International University. We both laughed as we mimicked American mannerisms of speaking English while jokingly describing how oddly some Ghanaian pronunciations of some English words sounded to audiences in America.

Nana also talked about loneliness. He said he did not come into contact with any Ghanaian in South Florida until the end of his fifth year. That year he met three Ghanaian families at the immigration office while in the process of securing valid papers as a migrant. These families became his links to other Ghanaians. The contact with these families and other subsequent ones set the tone for the formation of the Association. He said his biggest challenge had to do with securing valid papers as a migrant:

So I came to Florida from Liberia, not knowing anybody in Florida who could lead me to things I wanted to. Things were very difficult and challenging especially with this green card process. I had to wake up early in the mornings around $3 \mathrm{a} . \mathrm{m}$. to queue for an interview at the immigration office. On some occasions, I had to seek the help of lawyers to help with the process and I did not know any Ghanaian lawyer. The thing is if you are working with your own people, it is good. They understand you better and will go to great lengths to help you.

While he identified problems he faced speaking English and Spanish in South Florida, Mr. Kupim said his major challenge as a migrant was securing papers to legitimize his stay as he had entered the country illegally. "Not having legal papers alone scared me. I was afraid to go out there to find work. They would ask for my social security or any sign indicating my immigration status in America and I knew if they found out that I was illegal they could deport me." I sensed his reluctance to discuss into details how he finally acquired his legal status, so I did not press further. He only said, "But finally I got 
a legal status. So, I am now a legal resident." He also mentioned how things would have been easier for him if he had known some Ghanaian lawyers operating in the city.

Mrs. Mumu $(40+)$ also shared her experiences with what she saw to be expressions of racism. "You know what ... at one time while on the bus; I sat by a white lady. Could you believe she stood up immediately I sat by her? The funny thing was that all the other seats were filled. This means she decided to stand rather than sit by a black woman. I was stunned at first, but when the reality of what was happening sank in, I became very annoyed."

Kuku, a single parent, shared a recent ordeal at work in July 2013 which brought home to him some harsh realities of being black and an immigrant in South Florida. A dead body was found in a container in which he was working on at a dock. He indicated that the situation was complicated because he was the only person who had access to the place. "So naturally I was the prime suspect," he said before providing details of his ordeal.

My race made it even worst. They wasted no time in handing me over to the police who vigorously interrogated me for two days. Then my luck came. The officials of the company remembered that there was a camera in the room. When they played back what the camera had recorded it showed that the deceased sneaked into the container and had become trapped in it and suffocated to death. That was what saved me. Efua, [my name] you can imagine what would have happened to a black man like me if there were no cameras. I would have been jailed. This incident made my life miserable close to a month. I barely had time for my children; I only get to see them on weekends since I have to leave early in the mornings and come back late in the night when they are in bed.

He ended the story describing how he had to face the ordeal all alone as he did not have many friends. He noted that there is the need to have people to share your problems with 
when experiencing difficulties: "In times like this, you really need people to talk to and share your problems with. You need people who understand you and have similar experiences," he emphasized.

I became friends with Mame Ohenewaa (simply called Ohenewaa) the first time I went to the Association's meeting in July, 2013. That day she was the only person dressed in the traditional Ghanaian woman's cloth called slit and kaba and that drew my attention to her. After the meeting, she approached me and asked for my number. She has a reputation in the Association for calling members at least once a week to see how they are faring. She calls me "mi nana," meaning "my grandchild," a reference to her status as one of the oldest members of the Association. After my initial meeting with her she would call me at home every week to check on me, inquire about my studies and other happenings in my life, which I appreciated very much. Ohenewaa is in her late 70 s or early 80 s, and has been in South Florida for about twenty years now. She lives in Fort Lauderdale.

Ohenewa said she came to America through her ex-husband. However, the marriage collapsed almost immediately after she got to America, leaving her to fend for herself. New to South Florida, and barely able speak any English at the time, she had to "do it all by herself." Fortunately, a Ghanaian basket weaver, a woman, employed her. Because she was paid less than the minimum wage at the time, she had to supplement her income by doing other odd jobs. She was also employed in a bakery, but the work was challenging because she could hardly speak English. She also talked about having no place of her own and having to spend nights on the living room couches of friends occasionally. 
My interview with Ohenewaa was very emotional. Her eyes were filled with tears when she would describe, with some reluctance, one ordeal after the other. I attributed her reluctance to her desire to leave these horrid pasts behind her. Sometimes I would divert the direction of the conversation by introducing an entirely different theme, to enable her regain her composure. But her narrative contained episodes of joy too. During these moments she would smile or laugh while talking about meeting old friends at gatherings, and sharing stories of their pre-departure lives with them after she had joined the Association. A devoutly religious person, Ohenewa attributes her survival in South Florida to divine intervention. She would end our interchanges with expressions such as, "but God saw me through. I gave and still give all to God- He knows best." For her, even the fact that Ghanaians now have an Association was God's making as this provides a context in which many members find solutions to problems they face as migrants.

When Nana found out I was from Agona Swedru, a town in the Central Region of Ghana, he insisted on my meeting Fati, one of the Association members who comes from Agona Swedru too. He spoke a lot about Fati. Eventually I met Fati at one of the funerals of the Association. In the course of exchanging pleasantries, Fati revealed how well she knows my family; she is a close friend of one of my Aunties. Fati is in her mid thirties, resides in Fort Lauderdale, and has been in South Florida for almost eight years. She came to South Florida on the invitation of her husband, who is more than twice her age. They are now divorced. She recalled how her husband maltreated her just months after she joined him. "I had to find a way out of the marriage before I was sent to my early grave," she said, after describing the "torture" her husband subjected her to during the marriage. She described how a Haitian lawyer, who Fati's work mate introduced her to, 
helped her to file for divorce. The Haitian lawyer also introduced her to his Ghanaian friend, who helped Fati secure a new apartment. At the moment, Fati is a licensed hair stylist. She has her own salon where she does hair braids for most of the women in the Association. Concluding her account, she pointed to the crucial need for migrants to have links with each other, making references to how such links came in handy when she needed help.

The narrators of these accounts did not explicitly link their joining the Association to these challenges. Their accounts, however, provide us with hints about the benefits that made their membership of the Association worth the while: the need to have a group of fellow countrymen and countrywomen to help with challenges, frustrations and ordeals that individual Ghanaian trans-migrants experienced in America. One thing that stood out was their desire to have people they could rely on. This, among other reasons, was why they joined the Association.

\section{It Paid Off}

In my interviews with Uncle and Nana, pioneers in the formation of the Association, they indicated that apart from some of the challenges I have enumerated above, some of the Ghanaians they came in contact with before the creation of the Association, complained about " "missing" the "life back home," "the strong sense of community Ghanaians share," "local Ghanaian foods," "sharing jokes in the Ghanaian languages," and other aspects of Ghanaian culture, such as singing, drumming and dancing. Such complaints, as

the leaders indicated, generated the thought of "coming together or meeting once in a while as Ghanaians." When one of the Ghanaians lost a mother-in-law in 1992 there was a very strong presence of Ghanaians at the funeral. Those who attended also contributed 
money and other resources to help with the funerals. One leader described what followed after the funeral:

That was when we saw for ourselves the straight of our huge number in South Florida. We did not know we were that many. We felt it was time to create a formal group that would meet regularly, rally resources, organize cultural events, help each other and make our presence felt here in South Florida. ${ }^{68}$

Since its creation the Association, which regards itself as a Ghanaian family or community and not just as an Association, has served diverse purposes for those who have joined. Clearly from the experiences and challenges of Ghanaian migrants discussed above, they expressed a strong desire of affiliation and proximity.

They were however uncertain as to how, where or when to start and also, what to discuss at such meetings. These uncertainties were resolved at the funeral of Cliff Lartey's mother-in-law in 1992. Uncle, Nana and a few others started meeting occasionally to discuss how "Floridian" Ghanaians could support bereaved Ghanaians. Since then, the Association which represents a Ghanaian community, has been very instrumental in the lives of members and non-members alike.

Serving as a Linkage to Ghana. According Auntie Mumuni (Mumuni), "one of the best decisions I have ever made is joining UGASF. It is the one of the best things that has ever happened to me." She resides in Fort Lauderdale and has been an active member of the Association for about five years. Discussing the role of the Association in the lives of Ghanaians, Mumuni maintains, "For me this is like being home, you know. I get to speak Twi, laugh like how I used to back home. I get to joke in my local language and people understand the context. It is so difficult saying Ghanaian jokes in the English language."

68 Kwaku, interviewed August 10, 2013. 
Thus to Mumuni, the Association is not only a link to Ghana, but also reminds her of Ghana.

Like Mumuni, Aminatu also indicates how the Association provides a link to Ghana through Ghanaian foods. She notes, "I always yearn for our monthly meetings and other social gatherings. This is the only time I get to eat or buy Ghanaian food. Some members bring traditional food to be served at meetings, while others sell Ghanaian food stuff. You can get Ga and Fante Kenkey, palm oil, shito among others. Some also sell traditional fabrics and dresses. Regardless of what you need or want, there is someone to contact in the Association."

Members also participate in events in the lives of Ghanaians back home. The Association, as part of creating a quasi-Ghanaian community in America, organizes events on Ghana's Independence Day celebration, periodic picnics, and displays of Ghana's culture among others. Below is the inscription on the flyer for Ghana's Republic Day celebration n South Florida.

When was the last time you had so much fun?

The United Ghanaians Association of South Florida, Inc. celebrates

The 53rd Republic Day Anniversary of Ghana

We invite you, your family and friends to join us at

Amelia Earhart Park, East 401 East 65th Street Miami, Fl 33013

Park Phone: 305-685-8389

IT'S TIME TO PLAY BASKETBALL, TENNIS AND/OR VOLLEYBALL IT'S A FUN-FILLED DAY $\sim \sim$ IT'S A FUNFILLED DAY

SATURDAY, JULY 13, 2013, 10:00 AM- 5:30 PM

Another member, Ekua, also shared her benefits from joining the Association. Ekua is twenty one years of age, a student at Miami Dade College and lives with her parents in Miami. She has been in Miami for less than a year. She is a very shy person and was 
hesitant to grant me an interview when I first contacted her. However, when she later found out we hail from the same village in Ghana, she consented. She complained of how difficult it has been making friends at school. "My school mates always say I have an accent so they cannot understand me when I talk. But they also have an accent; I can hardly understand what they say." I must admit that since I am also in my twenties, my relationship with Ama was more informal as compared to the other adults I interviewed. When Ekua raised the issue of accent, I jokingly asked her to pronounce "earth and daughter." Her pronunciations "eath and duaghta" are the typical Ghanaian pronunciations where the " $\mathrm{r}$ " is silent and the " $\mathrm{t}$ " highly emphasized. I teased her with the following remark, "You see, that is why your class mates have difficulty understanding you. Next time, try emphasizing more on the "r" and less on the "t." We laughed over that. But the fact remains that, although Ekua has not been a member of the Association for long, she feels more comfortable and relaxed in the midst of other Ghanaians. She need not worry about accent when she communicates. She always looks forward to the monthly meetings and also other social events where she "gets to interact with people the Ghanaian way." ${ }^{69}$

Coping/ Settling as Trans-Migrants in America. The Association also supports members in need of work, accommodation or any other life-related services. This is usually done through announcements during meetings that "so and so needs a place/ work so if anyone knows of any job opening please contact so and so at ...." Fati, the hair stylist was a beneficiary of this. When it was announced at the monthly meetings that she was in need of financial support to acquire a license to operate as a hair stylist, some members

${ }^{69}$ Ekua is one of the few "young" friends I made at the Association. It turns out she knows how to braid so she does most of my braiding. 
volunteered to support her. For Fati, apart from the fact that the Association supported her in opening her salon, the Association is also a money-making avenue. She is one of the two Ghanaians who braid the "Ghanaian way." This means she braids for most of the women who, in turn, bring in other customers, Ghanaians and non-Ghanaians. "Members always recommend me to especially their Haitian and Jamaican female friends. I occasionally have some Nigerian customers as well. I make a living out of this." I must point out that when Nana first introduced me to Fati, he remarked, "she is a hair dresser and she is very good." Her braiding skill is not recognized only by the females but by the males as well.

There have been instances where members have rendered supports to Ghanaians who are not members of the Association. Two members I interviewed indicated how they met a man who had come from Ghana but had nowhere to stay. He was virtually sleeping on the streets in Downtown Miami. The man in question, based on the "fanciful" stories most Ghanaians have about the land of America, travelled to Miami in search of greener pasture. He however, did not make adequate provision for his stay. He might have used the home address of someone in Miami during his visa application. The two members "had to take him to our home ... but we made him understand that we can only provide for him up to a certain time. He needs to get a job and find an apartment." The man I was told is now working at Wal-Mart and has his own apartment. Although he was not a member of the Association (he is still not a member), members of the Association helped him settle in America.

Kwamena, a male interviewee, age 28, and an international student at the University of Miami, also recounted how the Ansah family provided free accommodation 
and food for almost a year when he stayed with them. He indicates, "You know the life of an international student in Miami. You hardly have enough money. The ... family took me into their home where I had my own room and also fed me. I felt like a member of the household." When I interviewed Mrs. Ansah enquiring why the family supported Kwamena, she indicated, "We did not take any money from him... As an international student, we knew he had not enough money. Someone introduced him to us at the Association and said he needed a place to stay; we had a spare room, so we asked him to move in with us." ${ }^{70}$ Since I started this research, I have received couple of phone calls from some of the members indicating they have rooms at a cheap rate for rent (between $\$ 300-\$ 400$ a month, including utility bills). They always require that I inform especially the Ghanaian students. The support for Ghanaian international students and others is thus regardless of whether they belong to the Association or not.

With the problem of accommodation as a major challenge most of the members face in America, the Association is considering "building a complex to serve as a temporary 'Ghana House' for migrants in need of a place."’1

Economic and Other Supports. Economic support is usually seen in terms of funeral contributions where the Association, out of the monthly dues, donates $\$ 200$ (now $\$ 1000$ ) to the bereaved family. Since the Association acknowledges that neither the $\$ 200$ nor the $\$ 1000$ is enough to help recover the expenses the bereaved family incurred, individual members are encouraged to make personal donations to the bereaved member (s) or families. Funerary support extends beyond money to include; members attending the funerals or memorial services. Most of the members indicate how supportive the Association has been and still

${ }^{70}$ Mrs Ansah, interviewed July 28, 2013.

${ }^{71}$ Omane, interviewed July 29, 2013. 
is in "times of family bereavement" both in South Florida and Ghana. In my interview with Auntie Mumu, who lost her grandmother in Ghana, she indicated that the "give away gift" at the funeral in South Florida, in the form of a key holder, was donated by the abusuapanin. She also mentioned that the caterer was a member of the Association who more or less provided the service free of charge. Likewise, the services of the master of ceremony, the preacher and the individuals who sang at the funeral were offered free of charges.

Fig. 13 One of the Association members collecting donations from other members on behalf of a bereaved family during a funeral in Fort Lauderdale.

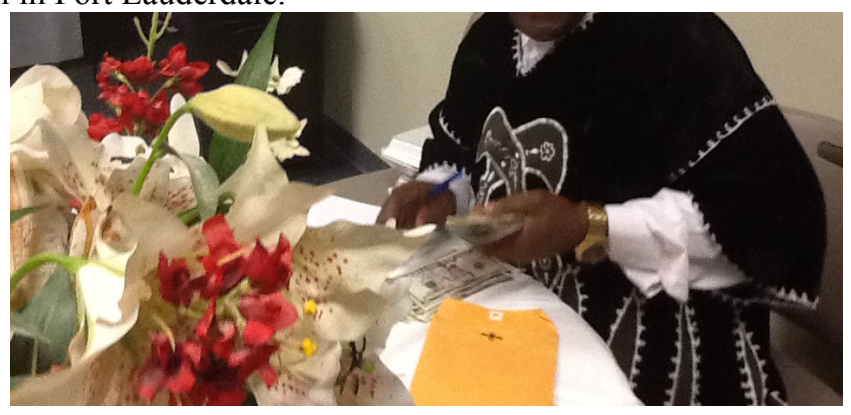

The economic and other supports are not limited to Ghanaians in South Florida but extended to the homeland, Ghana as well. The Association financially supports members with the cost of airfares for relatives in Ghana to travel to South Florida to be part of funerals in South Florida. Members also send money home and some buy "foreign drinks" for funerals performed in Ghana. For the most part, the involvement of members and the Association at large in the lives of other members is because "we are all in abrokyire and are aware of the hardships in this country, especially as foreigners and black people. All we have is our Ghanaian identity ....72

72 Omane, interviewed July 29, 2013. 


\section{Conclusion}

This chapter has discussed the "push factors" factor that forced Ghanaians out of Ghana and the "pull factors" that drew them to abrokyire and finally to America in search of greener pastures. The "pull factors" include economic crisis, especially the economic depression in the late seventies and early eighties. Recounting the challenges and struggles of the migrants, I have demonstrated how the Association played a crucial role in their survival in South Florida. In the words of the president of the Association, "We do not know the concept of etua wu nyonko hua, etua duyem [the idea of refusing to lend a helping hand to a friend in need]. We are all human beings and we all feel pain. Rather the Association operates on the nkonsonkonson and ensa nifa dware benkum na benkum so edware nifa. That is, in "unity lies strength" and also "the right hand washes the left hand and vice versa.' Death, for instance, is inevitable., ${ }^{, 3}$ This inevitability of death has given rise to a process of identity creation among Ghanaian trans-migrants in South Florida.

In the next chapter, I discuss how funerals generate context for the creation of Ghanaian identity in South Florida.

73 Omane, interviewed, July 29, 2013. 


\section{CHAPTER 4}

\section{FUNERALS IN THE LIVES OF GHANAIANS IN SOUTH FLORIDA}

Based on interviews with members of the Ghanaian migrant community who belong to the United Ghanaians Association of South Florida (UGASF), I identify three types of funerals. The basis of this categorization is where the person died and where he or she would be buried. The most typical form of funeral practiced in South Florida are funerals of family members who died in Ghana or some other part of the diaspora and would be buried in Ghana. Although there would be a big funeral for the dead in Ghana, the Association still organizes one for the dead. It is not necessary for the Association to have known the dead personally; all that is necessary is for a member to announce the death of a dear one who was living in Ghana or elsewhere. All the funerals I participated in were of this kind, that is, for relatives of members who had died in Ghana or some other place. Funerals are also performed for members of the Association or their relatives who die in South Florida and are buried in South Florida. However, since no member or member relative died in the course of the research, I had no opportunity to observe any of such funerals.

A third type of funeral is that of members of the Association who died in South Florida but are buried in Ghana. A preliminary funeral is performed for them in South Florida, before the body is sent to Ghana for a bigger funeral. The discussion presented here is based largely on the funerals I observed, that is, of relatives of members of the Association who died in Ghana. This is not only because these were the funerals I experienced personally and can offer first-hand accounts of, but they provide classic examples to illustrate the argument I make in this chapter, that is, the fact that funerals 
integrate Ghanaian migrants in South Florida, offer contexts for them to perform their cultural identify, and enable them to participate in the lives of Ghanaians in the homeland.

\section{"It is Our Life"}

"You really want to know the function of funerals in our lives? Why, did you not grow up in Ghana?" This was the usual response I received from most of the interviewees when I asked them the question "what role do funerals play in your life as a trans-migrant in South Florida?" UGASF members do not think that being in South Florida should change the Ghanaian traditional essence of funerals in their lives.

\section{Identity Creation, Cultural Preservation \& Promotion}

An important function of funerals in the lives of Ghanaian trans-migrants in South Florida is that funerals help create a Ghanaian identity in South Florida and also provide the means for cultural promotion, expression and perseveration. According to Thomas Y. Owusu, "the fact that all Ghanaian ethnic associations have included the world 'cultural' in their names suggests that cultural issues are central to their objectives." ${ }^{.74}$ In the case of UGASF, the word "cultural" is not included in its name, but one of its objectives is to promote Ghanaian culture. A variety of traditional customs and rites, including the pouring of libation (to invoke ancestral spirits) as well as traditional dress, music, drumming and dancing which occasion funeral, provide avenues for the creation, promotion and performance of Ghanaian cultural identity.

\footnotetext{
74 Thomas Y. Owusu, "The Role of Ghanaian Immigrant Associations in Toronto, Canada" International Migration Review 34: 4 (2000), 116.
} 
Funeral celebrations in South Florida, like those in Ghana, begin with the announcement of the death of the deceased to relatives or friends. Unlike the traditional (oral) way of conveying such messages to relatives and friends in Ghana ${ }^{75}$ members of the Association are informed of a death via emails and phone calls, regardless of whether the person died in Ghana or in South Florida. The reason for using emails as means of communicating among members is that it is the most effective means to get any message across to members. Due to the busy daily life routines of most of the members, they seldom make social contact with each other outside meetings, making it is almost impossible to convey such messages orally. With emails, members are bound to receive the message on time. An example of such emails read,

The Boye family cordially invites you to a memorial service in honor of Ms. Grace Boadu- Boampong, the late sister of Mrs. Esther Boye. Please save the date and join us to show our love and support for Auntie Esther as she honors the memory of her sister.

Date: Saturday October 26, 2013

Time: $6 \mathrm{pm}-10 \mathrm{pm}$

Venue: Quality Inn Sawgrass 1711 N University Drive Plantation, FL, 33322

Preferred Attire: Black or Black and Red Contacts: Auntie Esther 954536-0876

The goal of informing members early is to give them adequate time to prepare to support the bereaved family financially or through other means to ease the burden of the funeral cost either in Ghana or in South Florida. One of the duties of the Association's secretary is to email members regarding any death reported to him or her by the bereaved individual or family. For some elderly members, such as the 80 year old Auntie Awo,

\footnotetext{
75 As discussed in Chapter 2, the use of the media and other forms of technologies in Ghana in conveying death related messages to relatives is a modern/ recent development.
} 
who seldom checks her emails or do not know how to access them because of "aversion to this American computer thing," emailing is not the "most effective" mode of reaching them .They prefer phone calls.

In Ghana the dead are buried on Saturday, so the funeral and burial take place on Saturday. In Akan religious discourse, it is believed that the day the deceased's breath of life (soul) returns to Onyame (God) the creator is Saturday. Following this tradition, Ghanaians in South Florida perform their funerals on Saturdays. An additional reason is that on Saturdays, most the members of the Association are off from work and are free to attend a funeral. Whereas funerals in Ghana are performed in stages, with each stage completed on a different day, in South Florida, every aspect of the funeral is completed on Saturday.

Also, Ghanaian South Floridian funeral ceremonies take place in the evenings, usually from 7-11p.m.instead of the usual Saturday mornings in Ghana. Members of the association who work during the day on Saturdays can only attend such occasion in the evening, making Saturday evenings the most ideal time for funerals. Since funerals, as understood in the Ghanaian worldview, are a time for families and loved ones to unite and support, especially, the bereaved, the Association makes a point of organizing the funeral at a time that most members can attend.

The Association is like the surrogate Ghanaian family in South Florida which offers social, emotional, and financial support to the bereaved family, regardless of where the death took place. The president of the association reiterated this point when making a funeral donation to a bereaved member during the funeral on October 26, 2013: 
Whenever we go for meetings we always ask if anyone is having a party, he or she should let us know. In the same way, if anyone is bereaved he or she should let us know; we leave everything in order to support the person. So we are here to make a presentation to ... You have been with us all these years and when a thing like this happen we cannot stay back as an Association while your family goes back and forth, we have to be with you. In our culture, we have to support you. Since this happened, the Association has been with you from the beginning till now. Whatever you are going through, we want you to know that we are here with you. This token is to support you. We know that you will be going to Ghana for the funeral as well. Know that we will continue to support you with our prayers and all that we can...

The Association has established a funeral fund out of which it makes donations to individual members when they are bereaved. All the same, some individuals generously donate money to help the bereaved with the cost of the funeral. I was impressed by the strong sense of obligation towards donating money to help others demonstrated by individuals. Some members said they set aside some money for such donations whenever they received their pay checks. Mr Bediaku, a 45 years old accountant from Port St Lucie, rationalized such donations:

You never know when it would be your turn to be helped. Death never tells any family when it would come. And when it comes the family may not be ready for it. So you need to help others when they need you so that you too will be helped when death unexpectedly strikes.

I also noticed that members of the Association saw the need to donate money as an expression of their "Ghanaianness," or sense of belongingness to the Association. This shared sense of the need to freely donate money and other resources to help individuals when their relative dies is one way in which the bond between members is reinforced. As discussed in Chapter 3, such need for a family to support bereaved Ghanaian transmigrants was the reason UGASF was formed in the first place. 
Fig. 14: The President and the Vice President of the Association giving the funeral donation (the envelope in hand) to a bereaved member on behalf of the Association

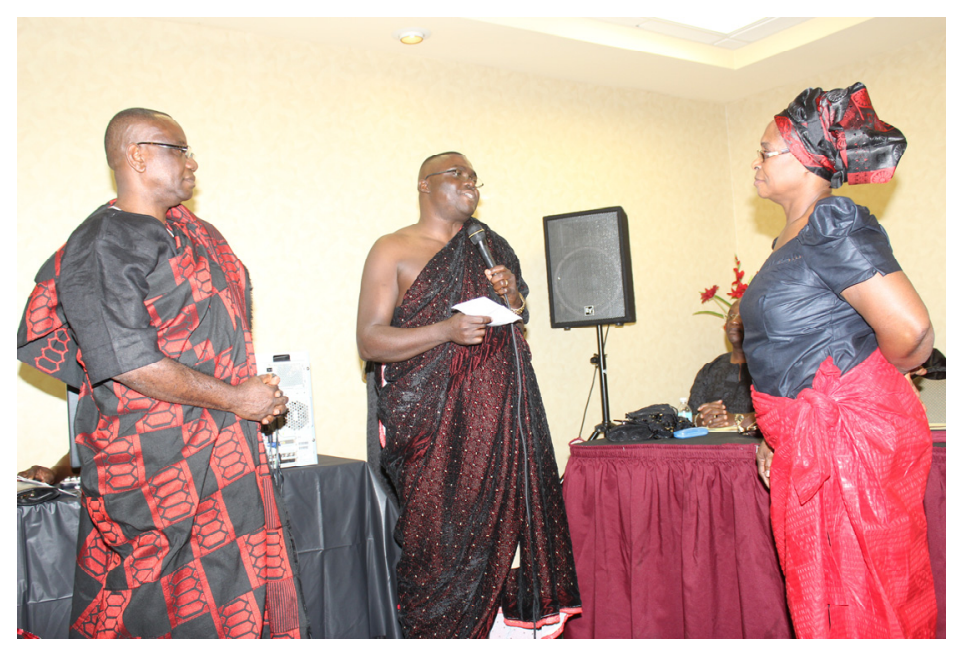

Also unlike Ghana, where funerals are held in an open space, including Friday night wake keepings, I observed that funerals in South Florida are held in an enclosed place such as a rented room in a public library. This severely limits what members can do. For instance, members cannot play loud music during the funeral as is the practice in Ghana This makes funerals in South Florida especially very solemn occasions in contrast with the enthusiastic and vibrant celebration in Ghana, particularly when funerals extend into the evening.

With the influence of Christianity in Ghana, most bereaved families attend church service on Sunday to thank God and also express their gratitude to the church for its support during a funeral in Ghana. During the burial on Saturday in Ghana, mourners and sympathizers are usually informed of the Sunday service and are encouraged to attend. This was not the case with the funerals I participated in, in South Florida. Because most of the members of the Association are Christian (Pentecostals) I expected to see a 
stronger influence of Christianity on the funerals. Yet there are no Sunday services in South Florida, at least, none that members were encouraged to attend during the research. Funeral cloths. One way of creating, maintaining and promoting the Ghanaian identity in South Florida is the use of Ghanaian funeral cloths. Members of the Association have maintained and still use Ghanaian funeral cloths for funerals in South Florida. The first funeral I participated in was on June 15, 2013. Since the deceased was an elderly woman (a grandmother of one of the members), the dress code was a traditional Ghanaian kaba and slit. $^{76}$ The colors could be either white or a combination of white and black, like the picture in Fig. 15. Since I did not anticipate attending any funeral in South Florida as part of my masters' program, I did not bring any Ghanaian funeral cloth with me. I was in a dilemma and had two options; either I wore a black jean with a white blouse or a black and white dress. I decided to go for the latter since it is culturally not acceptable for a female adult to wear jeans to funerals in Ghana, and I feared many members will frown on my appearance. And also, as a researcher in the group I did not want to be a "misfit" at the funeral. So I ordered a black and white dress on ebay.com. which I wore on that day.

${ }^{76}$ Kaba and slit is the name of a Ghanaian traditional style of a sewn cloth worn by women. 
Fig. 15 One of the women dressed in a Ghanaian kaba and slit style. The color is black and white for the funeral.

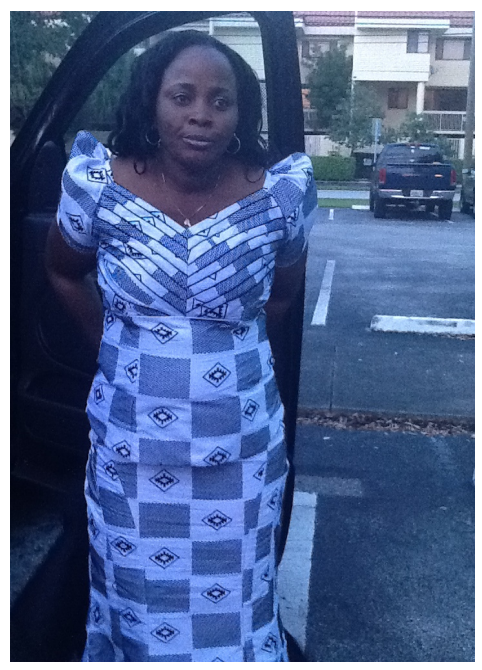

Because the funeral extended into the night, I had to spend the night with the Ansah family, which hosted the occasion. Ekua, whose room I shared, and I hardly slept that night; we chatted throughout about Ghana, moving from one topic to the other.

My second funeral participation was on October 26, 2013. Like the first funeral participation, I was confronted with the challenge of getting the right dress. The deceased was a younger woman so the dress code was either black or a combination of black and red. Again, I did not have a traditional Ghanaian red and black funeral cloth, so I wore black jeans with a red blouse. At the funeral, it turned out I was the only adult female in a jean or pant. With the exception of two young adults who were probably in their twenties, all the female adults were in the Ghanaian traditional funeral cloth. 
Fig. 16 I (on the left hand side) together with one of the women in a traditional Ghanaian red and black funeral cloth, kaba and slit.

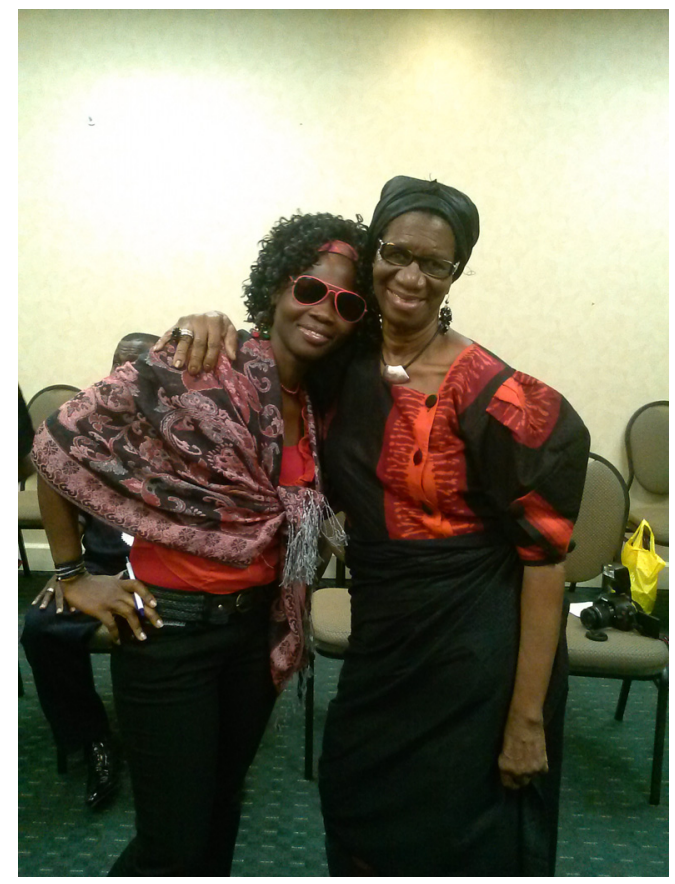

One woman who did not get the right code of color and had put on a white and a black appeared to be a "misfit." in the crowd. As if the inappropriateness of her dress was not enough, she was among the "chief mourners" who had to sit at the high table, making her odd color choice stand out. This stresses the importance of colors to funerals in the Ghanaian context. The color depicts a lot about the moods of the living as well as the status of the deceased.

The Ghanaian understandings concerning the cloth colors and design patterns in relation to the gender and status of the deceased, and the emotional expressions of the living have been incorporated into funerals held in South Florida. Wearing cloths in the colors red, black, white, brown or their combinations are common at Ghanaian South Florida funerals. It is for this reason that when Auntie Agie, one of the women in the Association, wore a white funeral cloth to the funeral of a thirty five year old in Fort 
Lauderdale, she felt "embarrassed and out of place as no other mourner was dressed in that way." 77 She lamented her predicament during a conversation with me, explaining how she did not "see" the color of the funeral cloth mentioned in the email sent to members of the Association. In an interview with some of the members as to why they still use the Ghanaian funeral cloths in South Florida, most of them, especially the women, maintained that the Ghanaian funeral cloths differentiate Ghanaian funerals from "American" funerals. This is what Aku, a mother of three living in Fort Lauderdale said,

You see how different the Ghanaian funeral cloths are? That is what makes it different from funerals in South Florida. If I wear this cloth, people always want to find out where I come from and where I got the fabric. I proudly tell them I am from Ghana. This really makes me proud. In addition, each time I put on this cloth, it reminds me of Ghana. ${ }^{78}$

Auntie Awo, who was standing next to Aku, interjected:

And it feels good to see others in the same funeral cloths at funerals. It reminds me of our common heritage as Ghanaians. We value and appreciate what we have." 79

I observed that, some "Ghanaian Americans" (Ghanaians born in America and have never been to Ghana) in their attempt to "fit" into this identity had also dressed in some of these funeral cloths. One of these is Mimi, forty-seven years and a mother of two. In my interactions with her, she indicated:

My interactions with members of the Association make me feel more of a Ghanaian than an American. And the best part is when I put on these

\footnotetext{
77 Auntie Agie, interviewed November 7, 2013.

${ }^{78}$ Aku, interviewed September 20, 2013.

79 Auntie Awo, interviewed September 20, 2013.
} 
cloths. I feel good and really connected with the women. I am not left out. I feel like I actually belong. ${ }^{80}$

To show off this symbol of pride, uniqueness, identity and as a way of promoting the Ghanaian culture, the women in particular constantly request relatives in Ghana to send them sewn funeral cloths with the "latest" design. When I visited Ghana in December, 2013, some of the women asked me to buy them some funeral cloths. Also, to avoid wearing the same funeral clothes all the time, I brought some new funeral cloths for myself.

Fig. 17 Members in traditional funeral clothes (red, black and white) during a funeral in South Florida

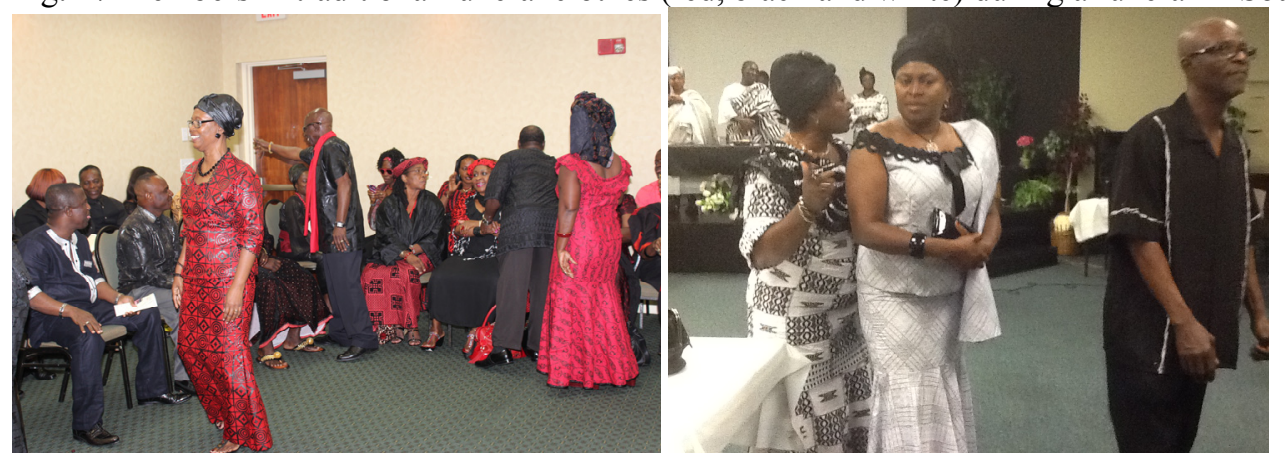

I must point out that there is a syncretization of the American culture with the Ghanaian culture at funerals in terms of the dress. Particularly with the second generation, there is not much emphasis on the use of the Ghanaian traditional funeral cloths during funerals. Most of the male youth wore either a black suit, or black and white suit and the females, black dresses. $^{81}$

The practice of mourners wearing dresses of the same color has an important role in reinforcing a sense of togetherness among them. Reflecting the grief that comes with

\footnotetext{
${ }^{80}$ Mimi, interviewed September 20, 2013.

81 I have discussed Ghanaian funeral cloths in Chapter 2.
} 
losing a dear one, the practice generates a shared sense of grieving. It is a symbolic way of saying "we are one people and your pain and grief (the bereaved) is ours too." Though the Association's insistence on every one dressing according to the color prescribed is inkeeping with Ghanaian funereal practices, one can argue that it is also a way of encouraging members to demonstrate their "Ghanaianness" at funerals. This is a very good example of performing Ghanaian identity in the context of funerals.

Using Photos of the Dead. Because the death occurred in Ghana, in the funerals I attended, pictures of the deceased while alive were substituted for the corpse. According to some of the members, pictures can still be used even when the death occurs in South Florida. Such pictures are placed in front of mourners and sympathizers during the funeral.

Fig. 18 A picture of a deceased (while alive) placed in-front of the mourners and sympathizers during a funeral celebration in Fort Lauderdale, South Florida.

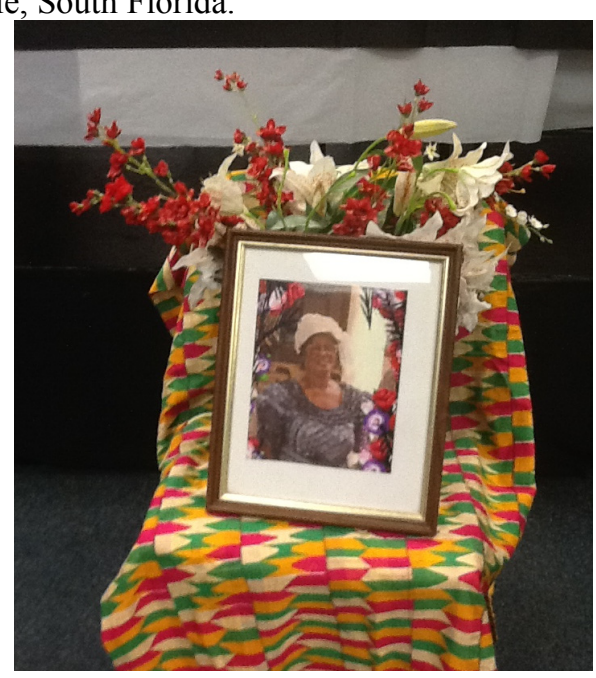

Just like a corpse, the deceased's picture is symbolic, reminding members of the mortality of human kind and the fact that "death is a ladder" which everyone would ascend. It would seem that the use of pictures of the dead have become an integral part of funeral celebrations in South Florida. According to members' explanations, unlike the 
traditional Ghanaian practice of a bereaved family having "full control" of the dead body, one does not have that "full control" of the dead body in South Florida. Bereaved families, for instance, cannot bathe or dress the corpse as it was done traditionally in Ghana; it is the responsibility of funeral homes. ${ }^{82}$ For this reason it is practically impossible to "have the corpse during our Saturday evening funeral celebrations, ${ }^{83}$ even if the person died in South Florida. An interviewee also lamented this situation,

You know, because in Florida the bereaved family does not 'dress' the dead body like we do in Ghana, that contact with the corpse is not there. You cannot really talk to the corpse as you can in Ghana. Even if you do, people who do not understand the Ghanaian culture will think you are crazy. Although we can cry it is not as it is in Ghana. The Florida setting is not conducive for that. ${ }^{84}$

Symbolising the presence of the dead, the photo maintains the bond between the living members and the world of the spirits of the dead.

Representing the corpse during funerals in South Florida, the dead person's photo becomes the focus of funerary rituals normally performed for corpses in Ghana. For example, I observed that the practice of "nkradea" (the act of conveying messages to the land of the spirit through the dead) for instance, still takes place regardless of the absence of the corpse. While members stare at the deceased's picture as they "pass" or "stand" in front of it, amidst tears, they utter statements like, "nantie yie" meaning, "have a successful journey." Such statements reflect the indigenous Akan religious belief that the

\footnotetext{
${ }^{82}$ As I have discussed in Chapter 2, with the emergence of funeral homes in Ghana, the traditional practice of bereaved families having "full control" of the dead body has waned.

${ }^{83}$ Omane, interviewed July 29, 2013.

${ }^{84}$ Mansa, interviewed November 4, 2013.
} 
dead is embarking on a journey. Wishing the deceased a successful journey to the land of the ancestors affirms the livings' sense of the link with the world of the spirits or the dead, asamando. A successful journey to asamando will result in blessings flowing into the lives of the living. This way, the link between the living and the dead in the homeland is still maintained regardless of where Ghanaians find themselves.

Equally noteworthy is the fact that the function of photos of the deceased in South Floridian Ghanaian funerals goes beyond maintaining the link between the living and the ancestors to maintaining the link between South Floridian Ghanaian transmigrants and relatives in Ghana. It is also a way for the trans-migrants to connect with and participate in grief of the people in their homeland, Ghana. When the late president of Ghana, John Evans Atta Mills, passed away in 2012, members of the Association participated in the celebration of the funeral by holding a funeral service where his picture was used instead of the corpse. A related practice in connection with the use of photography as a way of linking the diaspora and the homeland in the context of funerals involves the trading of funeral photos or videos between relatives or communities on both sides of the Atlantic - that is Ghana and South Florida. This way, both Ghanaians in South Florida and in Ghana, get to "see" those who attended the funeral.

As Kwesi Yankah noted about Ghanaian obituaries in the print media:

In listing the names of the mourners, care is taken not to leave out any name... And woe unto the radio announcer who, instead of listing all the mourners, gets tired or bored and abbreviates the roll call ... Since the announcement is part of the last respect to the deceased, all names must appear. Who knows if the deceased may be reading the newspaper or listening to the radio and taking note of all relatives whose names were not heard? He may take the omitted names to be opposition leaders working 
against him in his death: and in his wrath, he may decide to return and lay his icy hands on them. ${ }^{85}$

The pictures sent to either South Florida from Ghana or from Ghana to South Florida serve as the "listed names" to both the living and the dead.

Performing Ghanaian Identity through Food at Funerals. The kinds of food people eat and the ways in which they prepare, serve and eat them, demonstrate who they are and where they come from. Food is important signifier of a people's identity. Ghanaians in South Florida demonstrate their identity through the food they eat during funerals. Feeding those who come to mourn your dead with you is a Ghanaian custom that migrants in South Florida continue to practice. One observation I made is that, as it is done during funerals in Ghana, it is mostly women who prepare the meals for the funeral celebration and serve it in South Florida. The men provide the drinks for the occasion.

Fig. 19 Women serving the food during a funeral ceremony in Fort Lauderdale

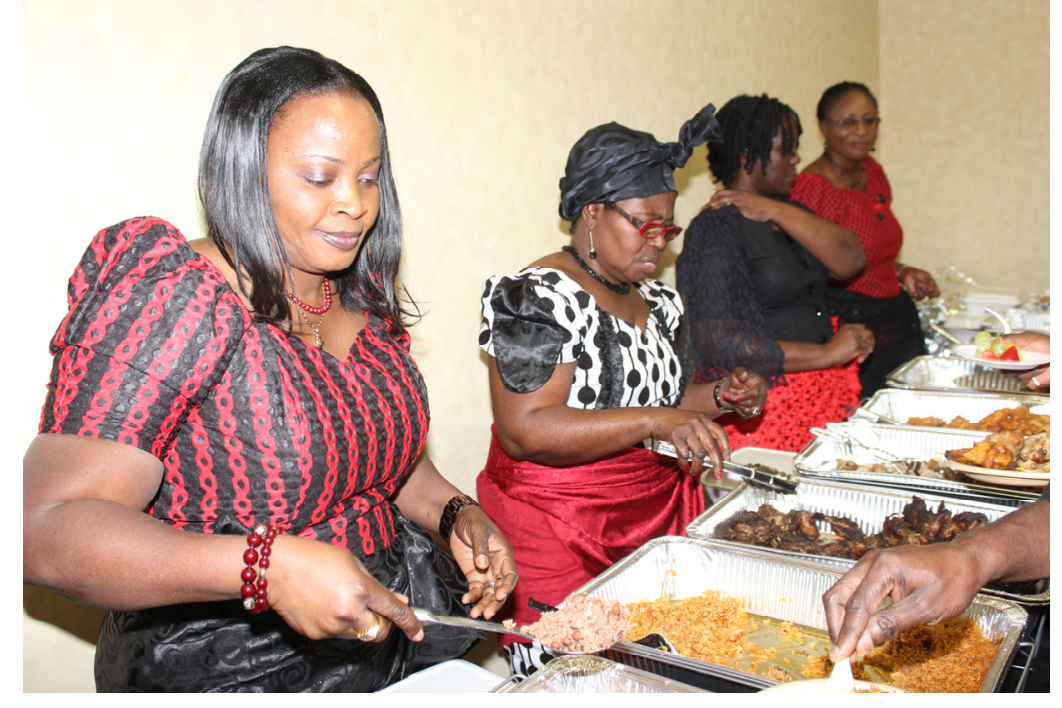

${ }_{85}$ Kwesi Yankah, Woes of a Kwatriot: Reflections on the Ghanaian Situation (Accra, GH: Woeli Publishing Services, 1990), 17. 
"I think I would like waakye. Is there talia and shito? Is the shito hot?" "Do you have banku or kenkey with hot pepper and tilapia? Is there nkrumankwen?" "Oh, there is fufu-great! I think I will have that." "Can you get me omu tuo ni nkatsinkwen?" "There is ampesi: brodea ni bayire." These requests and comments demonstrate the vast array of Ghanain delicacies typically offered guests at Ghanaian funerals in South Florida. Wakye is cooked beans with rice. Normally, a colored leaf is added to the rice and beans to give it a brownish or reddish color. Wakye is often eaten with cooked talia (spaghetti) shito, a sauce made with powdered shrimp, ginger, pepper and onion. Banku is a thick paste of cooked corn dough and cassava dough. It is usually eaten with hot pepper or nkrumankwen, okro soup. Оти tиo is cooked rice moulded into ball like shape and usually eaten with nkatsinkwen or, peanut/groundnut soup. Ampesi could be cooked brodea, plantain, or bayire, yam, which is eaten with sauce or soup. Almost all of these dishes are eaten with the hand (they can be eaten with cutlery as well).

For members, eating with the fingers "brings out the original taste or flavor in the food" more than eating with "fork and knife." Also there is a sense that eating with the fingers "makes one feel just like eating in Ghana," as it is a Ghanaian custom to eat with the fingers of the right hand. ${ }^{86}$ Even though many Ghanaian families prepare Ghanaian dishes in their homes, many respondents describe funerals as one of the times members get to eat Ghanaian dishes in public and demonstrate "their Ghanaian selves."

${ }^{86}$ Emefa, interviewed October 10, 2013. 
Fig. 20 Some Ghanaian food at a funeral in Fort Lauderdale, South Florida

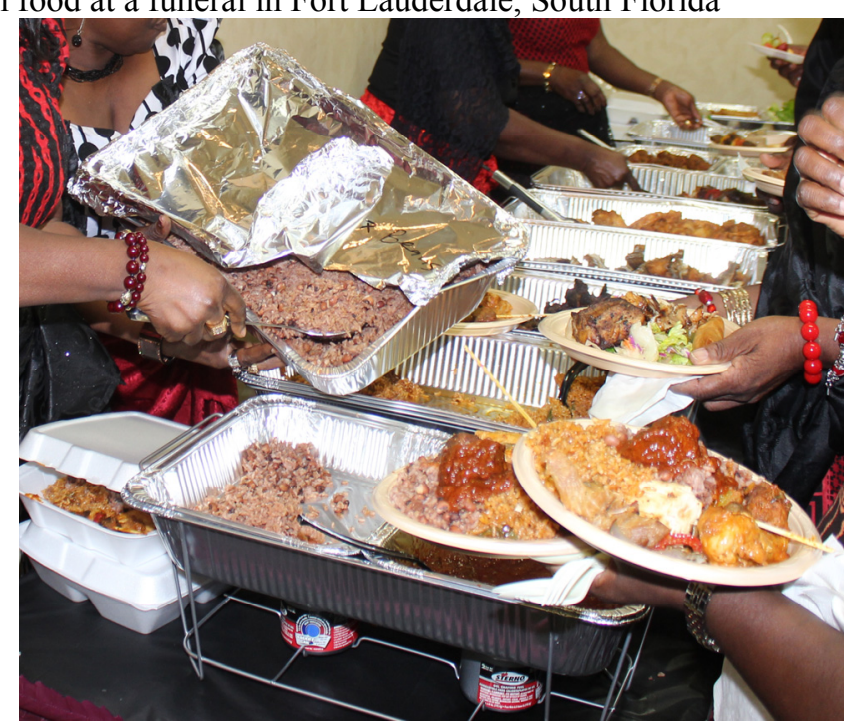

"Non-Ghanaian" dishes such as hamburgers are also served at funerals for members from the second and third generations, many of whom seem to prefer Western dishes. It is not clear whether these generations preferred "non-Ghanaian" dishes to Ghanaian dishes because they do not know how to eat with their fingers or they simply did not like the taste of Ghanaian food.

Music. The use of Ghanaian songs during funerals is another way trans-migrants from Ghana perform their Ghanaian cultural identity and preserve the Ghanaian culture in South Florida. I observed that the genre of music played in the funeral in South Florida followed the pattern in Ghana. Because of the pervasive influence of Christianity, Ghanaian funerals begin with Gospel songs even when the deceased is not a Christian. Other "non-Christian" songs, especially Akan highlife tunes are played afterwards. In the South Floridian Ghanaian funerals I participated in, the music was mostly from the Ghanaian gospel genre--I did not hear Ghanaian popular highlife songs. Because Akan people predominate in the Association most of the songs played or sang at the funerals 
were in Akan. On a few occasions I heard $G a$ songs. There were a few songs in the English language, but these were performed by Ghanaian artists.

In a typical funeral in Ghana professional traditional music/cultural groups can be invited to perform and are paid a fee. The intention of such performances, mostly of local dirges, is to console the bereaved family as well as entertain the guests. In South Florida individuals, that is, non- professional singers, have taken the place professional singers at funerals. But these individuals do not sing any local dirges. They only sing Ghanaian Christian songs, even though the intention is still to console the bereaved as well as entertain the guests.

Fig. 21 On the left is a picture of a Ghanaian cultural/singing group. On the right is an individual singing to console a bereaved family during a funeral in Fort Lauderdale, South Florida.

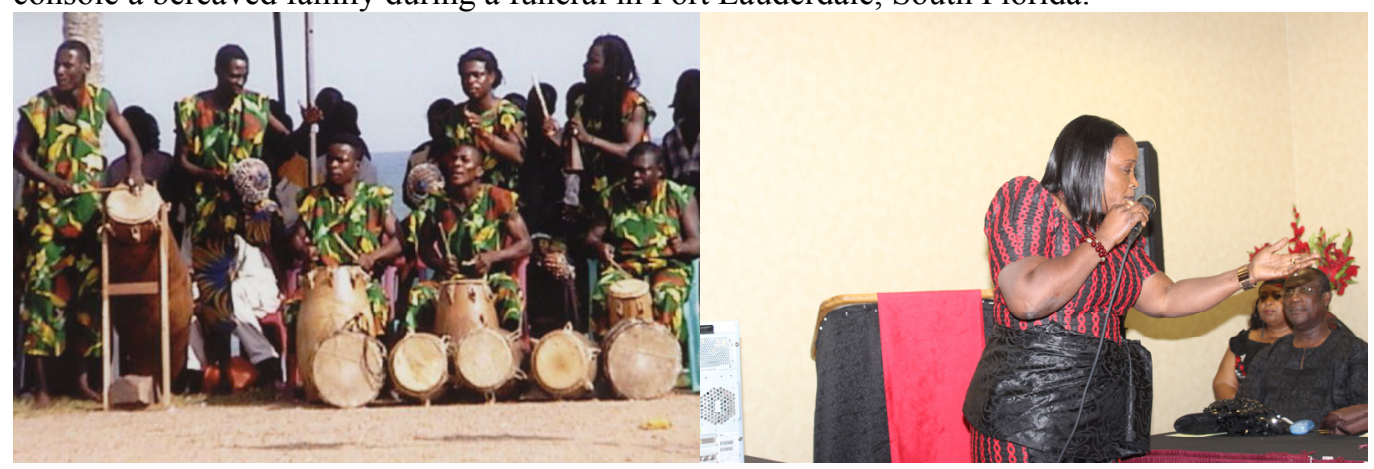

Dance/Cultural Displays. The singing at funerals in South Florida is often accompanied by dance or a form of cultural performance. According to Owusu, "in accordance with their desire to portray and maintain aspects of their culture, traditional associations have formed traditional dance groups (in the Ghanaian diaspora in Toronto)." ${ }^{97}$ In the case of UGASF, there are individual traditional dancers as well as the moframofra (children) and the sankofa (going back to the past) groups. These groups are not just traditional dance

87 Owusu, "The Role of Ghanaian Immigrant,"1167. 
groups. They also dramatize certain aspects of the Ghanaian culture such as marriage, naming ceremonies, and the installation of traditional rulers during funerals and other social events. These dramatizations are a way of displaying the Ghanaian culture, especially to "Ghanaian Americans" and other non-Ghanaian guests.

Fig. 22 A picture of moframofra and sankofa groups during a function in South Florida.

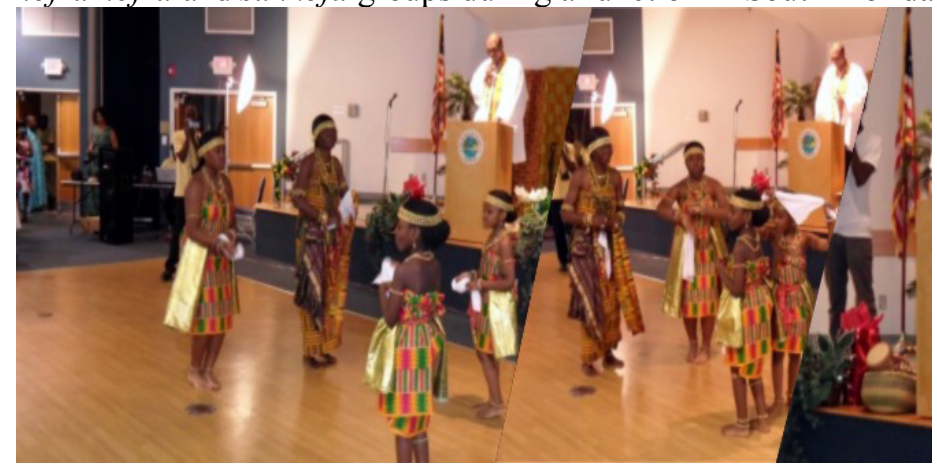

It would seem however that the sankofa and moframofra groups are not as active as most dance groups in Ghana. The members of these groups ( 25 and below) are young and "Ghanaian-Americans" who do not seem to have fully grasped the value or importance of such cultural performances, especially in terms of how they can instill "Ghanaianess" in performers. When I enquired from Kofi, who is eighteen years of age and lives with his parents in Miami, why he was not part of the sankofa group, he replied, "I do not want my friends to see me do this. Some of the steps are funny." Clearly, Kofi's concern about what his American peers or friends might think of him "doing" a Ghanaian dance outweighed any other considerations. He seemed less concerned about the Association's emphasis on preserving or promoting the Ghanaian culture in America. As a result, individual elderly women members perform the traditional dances, particularly the adowa dance, during most funerals. 
The fact that the youth do not share their enthusiasm for promoting Ghanaian culture seems to concern most of the elderly members. Many of them talked about how the thought of losing the Ghanaian culture, customs, traditions, values and social practices because their children did not show interest in promoting these, gives them sleepless nights. For example in my interaction with Mr. Ayivor, one of the male elders, he lamented, "It is always Auntie Efua. This woman is growing old. We need to train the youth to take over else all these will be lost to American culture." ${ }^{" 88}$ A lady in her late forties Auntie Efua, seems constantly eager to perform Akan dances during most of the funerals.

Fig. 23 A picture of Auntie Efua performing the adowa dance during a funeral in Fort Lauderdale, South Florida. Seated behind her are some members of the Royal House of Chiefs and Queens in South Florida.

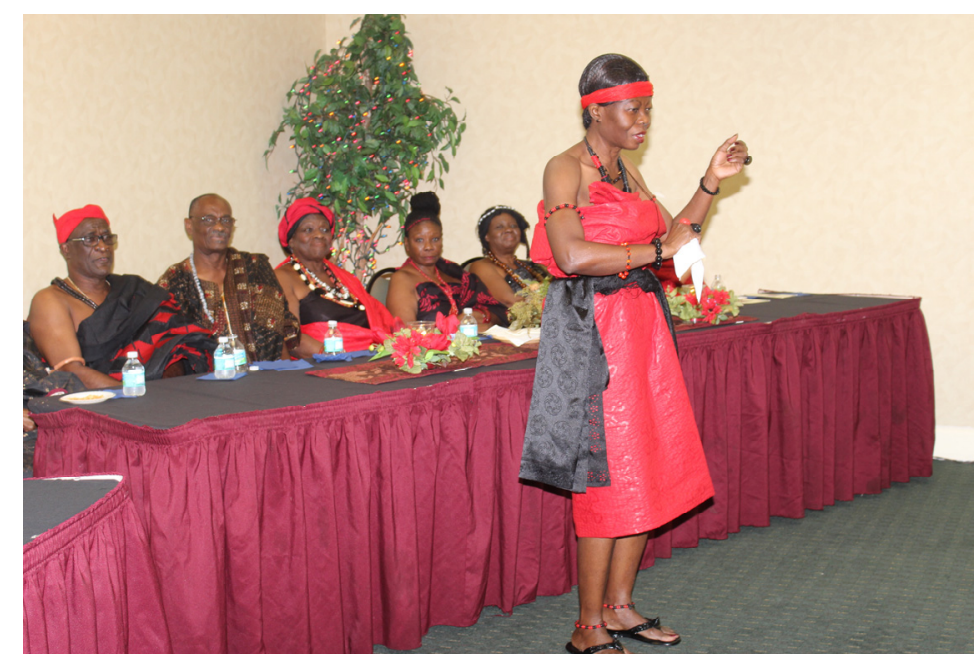

Aside from dance, other forms of cultural performances, dubbed "the cultural display" take centre stage at funerals. This is the time members seize the opportunity to showcase the richness of Ghanaian culture. One of such performances is the procession of members of the Royal House of Chiefs and Queens (traditional chief, queen mother, the linguist, et

${ }^{88} \mathrm{Mr}$ Ameyivor, interviewed August 26, 2013. 
cetera) that occasions most funerals in South Florida. The Royal House of Chiefs and Queens is modelled after the traditional leadership of communities in Ghana. There is the Nana (the chief), the Obahemaa (the queen mother), the okyeame (the linguist) and the council of elders. This modelling affirms Owusu's observation that, "as a way for immigrant Ghanaian ethnic associations to maintain their values, customs and traditions, traditional leaders in the diaspora resemble those back home so they have been given the exact same titles as those in Ghana." ${ }^{\prime 99}$ Through the procession at funerals, members of the Royal House of Chiefs and Queens display their traditional regalia, adorned with traditional beads. The aim of this display, as I found out, is to draw attention of nonGhanaian guests and "Ghanaian Americans" to the traditions that define Ghana, as well as to educate and teach the youth about the Ghanaian culture, that is, the values and beliefs that the regalia, gestures, and spoken words embody.

At a funeral, I met Amina and Sadia, from Nigeria and Jamaica respectively, who explained how they had come "to see how Ghanaian funerals are performed, and hopefully, join the Association. ${ }^{.90}$ I kept a close eye on them during the proceedings, reading their "body language" as they transfixed their gazes on the happenings. Their facial expressions exuded a mixture of beauty, shock and amazement. Throughout they traded commentaries about how beautiful the regalia and the beads were. After the funeral they engaged me in a long conversation about Ghana and Ghanaian culture. The two ladies are now "occasional" members of the Association. In a recent meeting with them they talked excitedly about saving money so that they can visit Ghana soon.

\footnotetext{
${ }^{89}$ Owusu, "The Role of Ghanaian Immigrant," 1167.

${ }^{90}$ Amina \& Sadia, interviewed October 26, 2013.
} 
Fig. 24 Section of some members of the Royal House of Chiefs and Queens during a funeral in Fort Lauderdale.

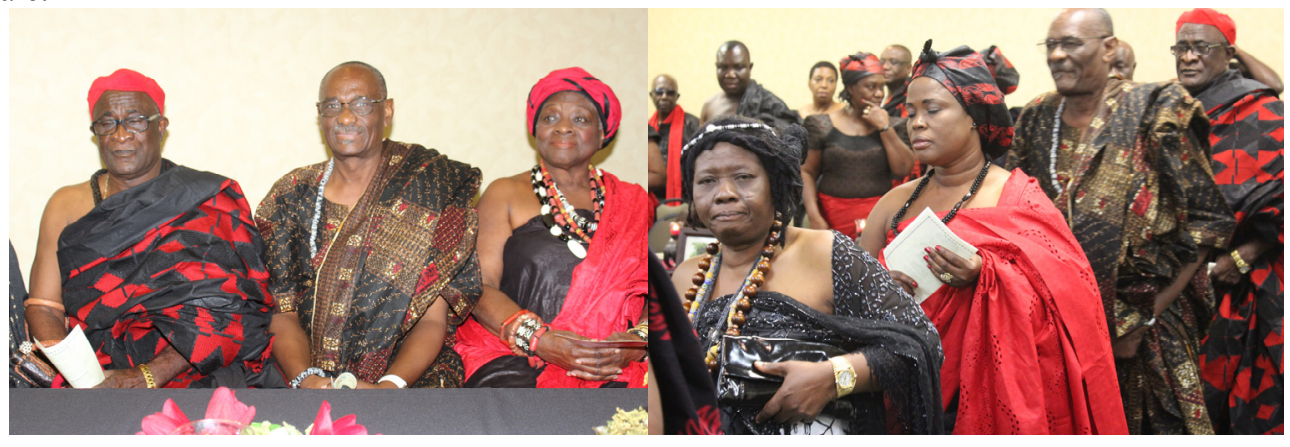

The procession of the members of the Royal House of Chiefs and Queens in Ghanaian funerals has become a permanent feature of South Floridian Ghanaian funerals. I was really intrigued the first time I witnessed the performance. In Ghana, traditional rulers will attend the funerals of members from a royal family or an important dignitary in the country like the president or a member of the House of State, but not the funeral of an "ordinary person." The fact that traditional leaders in South Florida attend funerals regardless of the status of the dead on the one hand, portrays that the status of these traditional leaders are more symbolic than real. On the other hand, it also indicates that the Association seizes every opportunity to perform their Ghanaian identity.

Language. "Oh, so you understand and speak Twi. Why are we speaking English?” This was the common reaction and response I got from members I interacted with when in the course of the interchanges they find out I understand and speak Twi or any other Ghanaian language. Such reaction and response was usually followed by "why are we subjecting ourselves to another person's language. Let us speak Twi" (or any of the Ghanaian languages, depending on the interviewee). Obviously, communicating in a 
Ghanaian language is a crucial aspect of performing identity among Ghanaian transmigrants in South Florida. It is for this reason that some members are against the use of English during the monthly meetings. Since there are "non-Ghanaian" guests during the funeral celebrations, most of the funerals are conducted in the English language with the occasional interpretation of a word or sentence(s) in a Ghanaian language. The portion of the funerals that facilitates the speaking of local Ghanaian languages is the meal that normally follows. This is also a context for members to have important social contact, have conversations, trade gossip and news about happenings in Ghana, South Florida and other Ghanaian diasporas; here members speak to each other in Ghanaian languages. Many respondents identified this as one of the most important aspects of the funerals they attend. "We get to talk to each other in our own languages and call each other the local names we were called in Ghana. Sometimes we even forget we are in America," Lizzy, a 40 year old attorney, told me, underscoring the place of language in performing Ghanaian identity.

Respondents described other ways in which funerals linked them to the homeland aside from the performance of funerals in South Florida for relatives who died in Ghana.

For example, Kiki, a forty six year old man who lost his sister in 2013 had this to say,

Although I am in America, when my sister died, I still wanted to perform the necessary rituals for her. Spirits are not bound or limited by location, they can function everywhere. Whether in Ghana or in America, if the dead are not properly buried, the living will incur their wrath. On the other hand, the proper burial brings blessings. In a foreign land, you need more of their blessings and protections. We may add a few of the Western elements, but we still hold on to who we are. ${ }^{91}$

91 Kiki, interviewed October 9, 2013. 
Clearly, from KiKi's response, funerals are an avenue for trans-migrants to enjoy the blessings of asamando which are needed most in "foreign" lands. Such blessings are geographically not limited. The Association ensures that as a family, the right postmortem rituals are performed whether someone died here or at home. I also heard story after story about how members had to travel to Ghana to attend funerals and what they did to help make home funerals successful. Many respondents also told me of the practice of family members flying into South Florida from Ghana to attend funerals of members who were buried in South Florida.

\section{Conclusion: Can We Survive?}

The themes that run through my observations and my interchanges with members of this Ghanaian Association in South Florida regarding the role of funerals in their lives as trans-migrants in South Florida is that funerals are avenues for creating and performing a Ghanaian identity in South Florida. They also talked about how funerals provide avenues for connecting with and participating in the lives of relatives back in Ghana and vice versa. In the context of funeral rituals, Ghanaian food, music, dance/cultural displays, and language demonstrate the common bond the members have. Cultural performances such as the royal procession generate a collective sense of pride in Ghanaian culture, reflecting popular Ghanaian proverbs such as "obi nfa nisa benkum nkyere negya fie" and obi nyi ninsuni nku na ofa fufuronshem, literally translated as "no one points to the father's house with the left hand" and "no one throws away his or her intestines and puts in another or a new one." The idea expressed here is that people must hold on to their identities no matter how negatively others might perceive it. The use of the left hand is frowned upon in Ghana, hence, the idea the proverb conveys is that no matter how bad a 
person's family or identity one has, it cannot be disregarded. Can Ghanaian transmigrants in South Florida survive without this identity?

On the basis of this, I argue that, the functions funerals play in the lives of Ghanaian migrants, are akin to those that the formal religious traditions, such as churches, and mosques, play in the lives of Ghanaians in the diaspora, specifically in South Florida. 


\section{CHAPTER 5}

\section{CONCLUDING THE THESIS}

This chapter concludes the thesis discussion. It discusses the major findings of the thesis and also ties together the themes that run through the thesis. Recommendations for further or future research based on the findings are also discussed.

\section{Major Findings and Discussions}

Using the importance of funerals in the United Ghanaians Association of South Florida as a case study, the thesis focused on how the funeral, a rite of passage and not a primary setting for religious expression facilitates community integration, identity creation and generates a context for Ghanaian trans-migrants in South Florida to participate in the lives of relatives back at home. The idea of this study emerged from the realization that, although there is a growing literature on religious flows from Africa to the diaspora in the West, the bulk of this literature focuses attention on the ways in which religious flows from African communities function as mechanisms of adjustment for African migrants in their Western host communities. But there has been little or no attention given to the rites of passage that African migrants bring with them to the West. Identifying recent African migrants in the West as "trans-migrants" who live "between and betwixt" their African homelands and the diasporas, this emerging literature demonstrates how formal religious institutions facilitate these homeland-diaspora interactions. Others scholars have looked at how these migrant religious institutions generate contexts for creating and performing new forms of identity in the West. Specifically, indigenous African Pentecostalism and Islam in the West has received more attention from these researchers in the West. 
This thesis thus sought to show how practices of African migrants such as lifecycle rituals in the West- birth, marriage and funerals- which take place in settings we do not consider as primarily religious, not only filter indigenous African beliefs into the West but also furnish for African migrants contexts which perform functions similar to those performed by the formal religious organizations. It is within this context that this thesis focused on Ghanaian funerals in South Florida and how this ritual provides avenues for Ghanaian cultural self-expression, community integration, the creation and performance of Ghanaian identity in their newly adopted Western home, South Florida, and fostering links with the homeland.

On the basis of field research the thesis found out that the Ghanaian worldview of "two inter-penetrating and inseparable, yet distinguishable parts," $" 92$ namely, the worlds of spirits and humans, influence the daily activities of members of the Association. Although most of the members are Christians, especially Pentecostals, their understanding is underpinned by the Ghanaian worldview of the influence of the spiritual world. On the basis of this, these trans-migrants make the effort to incorporate Ghanaian post-death rituals such as nkradea even when the South Florida context is not conducive for such practice. Trans-migrants also ensure that the dead are not "spoken evil of" and also that the right colors of funeral cloths are used, depending on the gender and age of the deceased. Engaging in such practices is to ensure that trans-migrants do not incur the wrath of the dead.

Another finding is that Ghanaians in South Florida and those in Ghana are both in a trans-migrant state. Through funeral, cultural and other social events, both groups of

92 Okorocha, The Meaning of Religious Conversion in Africa, 52. 
"Ghanaians" simultaneously participate in the lives of the other, maintaining a continuous link. As part of the Association's trans-migrant status and continuous link with Ghana, it organizes events to commemorate occasions held in Ghana. For instance the Association held an event for Ghana's $56^{\text {th }}$ Independence Celebration in which members dramatized a traditional Ghanaian marriage and held a royal procession of Ghanaian queens and chiefs as discussed in Chapters 1 and 4. More importantly, Ghanaians in South Florida and in Ghana send pictures and video of mourners and sympathizers taken during funerals in South Florida and in Ghana. Through the pictures and videos, both Ghanaians in South Florida and in Ghana get to "see" those who attended the funeral and therefore participate in the worlds of each other.

In addition to the above, through funerals and other social and cultural events, trans-migrants create a Ghanaian identity in South Florida. According to Jacob K. Olupona, African ethnic identities in the USA are connected to migrants creating a quasicommunity of the homeland in the host country in "connection to, and remembrance of an African homeland." ${ }^{93}$ Such identity creation is also an avenue for trans-migrants to preserve and promote the Ghanaian culture. The eating of Ghanaian foods, speaking Ghanaian languages, staging Ghanaian dance/cultural displays and putting on Ghanaian funeral cloths during funerals are ways of creating Ghanaian identity, preserving and promoting the Ghanaian culture. Although in the process of this identity creation one is bound to find an incorporation of certain aspects of the American culture, such as the serving of hamburgers at funerals and the wearing of suits to funerals, there is a greater emphasis on the Ghanaian tradition. This is seen in Aku's comment

93 Olupona "Introduction," 4. 
You see how different the Ghanaian funeral clothes are? That is what makes it different from funerals in South Florida. If I wear this cloth, people always want to find out where I come from and where I got the fabric. I proudly tell them I am from Ghana. This really makes me proud. In addition, each time I put on this cloth, it reminds me of Ghana. ${ }^{94}$

Akua's comment affirms Anya P. Royce's definition of ethnic identity as "the sum total of feelings on the part of group members about whose [sic] values, symbols and common histories that identify them as a distinct group." ${ }^{95}$ Olupona adds that such creation is complemented by the emphasis on the cultural values of the homeland, where, "community members emphasize the importance of speaking their languages and hearing it [sic] spoken, the chance to enjoy special food delicacies, services, and events, often including ethnic markers such as flags and clothing styles..."96

The need to preserve and maintain Ghanaian ethnic identity explain why the unwillingness and reluctance of the moframofra and the sankofa groups to learn the Ghanaian culture is a concern to the elderly trans-migrants in the Association. However, this concern raises the issue of generational gap and what generations regard as valuable. Whiles the older generation like Mr. Amenuvor as discussed in Chapter 4 insists on preserving the Ghanaian culture in South Florida, Kofi, a third generation thinks otherwise. Such Ghanaian culture in the worldview of Kofi can be substituted with South Floridian or American culture.

Closely related to the above finding is the finding that, as part of the identity creation, Ghanaian trans-migrants use every opportunity they find to display the

\footnotetext{
${ }^{94}$ Aku interviewed September 20, 2013.

95 Royce, Ethnic Identity, 18.

96 Olupona, "Introduction," 4.
} 
Ghanaian identity. As discussed in Chapter 4, rarely do traditional leaders or rulers, particularly chiefs and queens attend funerals of a deceased who is not a member of a royal family in Ghana. But in South Florida the traditional rulers are expected to attend the funeral of any member regardless of the deceased's status. In as much as the presence of the traditional leaders at funerals become an avenue to display the Ghanaian culture, it also makes their status more symbolic than real.

Another major finding is that the Association is the "Ghanaian family" that economically, socially and culturally supports Ghanaian trans-migrants. Particularly with funerals, the Association "helps to cover the cost of funerals, and provide [s] emotional support for the bereaved members." ${ }^{\prime 97}$ The funeral support the Association offer members is as a result of the high cost of post-death rituals involved in the host country, America, and the homeland, Ghana. As discussed in Chapters 3 and 4, the Association regards itself as a family that looks out for members.

Another finding is the fluidity of the Ghanaian worldview. The flexibility of the Ghanaian worldview makes it possible for Ghanaian trans-migrants to incorporate aspects of South Floridian or American culture in their daily lives and in particular, during funerals. Corpses are substituted with pictures. The practice of nkradea is done to the deceased's picture instead of the corpse. Funerals are held in the evenings instead of the traditional mornings. Even though Ghanaian trans-migrants have substituted some funeral and other cultural practices, such substitutions do not lead to a loss of the essence of the

\footnotetext{
97 "United Ghanaians Association of South Florida," http://www.ghanasouthflorida.org, [accessed, May
} $3,2013]$. 
Ghanaian values or meanings. Through such inventions the Ghanaian identity or community is created.

\section{Recommendation: Areas for Further or Future Research}

On the basis of the findings of the thesis, I have demonstrated that cultural practices that do not primarily express religious beliefs such as funerals can equally play a crucial role in the lives of trans-migrants in the diaspora. Such cultural-religious practices help transmigrants cope in their "new home," create their ethnic identity and help maintain a continuous link with their homeland, Ghana. As a result of this, further research should be done on the other rites of passage with religious underpinnings to understand their roles in the lives of African migrants in the diaspora in the West.

In addition to the above, a comparative study can be done on how such nonformal religious ritual practices differ from those in the homelands and how such differences reflect as well as shape the lives of trans-migrants in the diaspora.

A study could also be done on why African women still play the domestic role of cooking and serving even in the West in spite of their exposure to new ideas about liberating women and sharing power with men. Why do not trans-migrant Ghanaian men cook or, at least, serve the drinks they provide at funerals?

I conclude on the note that the functions funerals play in the lives of Ghanaian trans-migrants in South Florida, are akin to those that the formal religious traditions such as the Ghanaian Presbyterian Church in New York and Ethiopian Orthodox Christian Church in Los Angeles play in the lives of migrants in the diaspora. Any study that focuses attention on African migrant religious experiences in the West must pay respectful attention to these rituals that are not performed in contexts considered to be 
primarily religious but perform functions akin to those performed by formal religious institutions all the same. 


\section{REFERENCES}

\section{Books}

Adogame, Afe. "From House Cells to Warehouse Churches? Christian Church Outreach Mission International in Translocal Contexts." In Travelling Spirits: Migrants, Markets and Mobilities. Eds. Gertrud Huwelmeir, \& Kristine Krause. New York/London: Taylor \& Francis Group, 2010.

Akinade, Akintunde. "Non-Western Christianity in the Western World: African Immigration Churches in the Diaspora." In African Immigrant Religions in America. Eds. Jacob K. Olupona, \& Regina Gemiggnani. New York/London: New York University Press, 2007.

Appiah-Kubi, Kofi. Man Cures, God Heals: Religion and Medical Practice among the Akans of Ghana. New York: Friendship Press, 1981.

Asare Opoku, Kofi. West African Traditional Religion. Accra, GH: FEP International Private Limited, 1978.

Biney, Moses O. From Africa to America: Religion and Adaptation Among Ghanaian Immigrants in New York. New York/ London: New York University Press, 2011.

Bowman, Leroy. The American Funeral: A Study in Guilt, Extravagance, and Sublimity. Detroit: Public Affairs Press, 1990.

Dahlin, Olov. Zvinorwadza: Being a Patient in the Religious and Medical Plurality of the Mberengwa District, Zimbabwe. Frankfurt am Main: Peter Lang, 2002.

de Witte, Marleen. Long Live the Dead: Changing Funeral Celebrations in Asant, Ghana. Amsterdam, NL: Aksant Academic Publishers, 2001.

Ephraim-Donkor, African Spirituality: On Becoming Ancestors. Boston, MA: Pearson Custom Publication, 1997.

Gyekye, Kwame. An Essay on African Philosophical Thought: The Akan Conceptual Scheme. Revised ed. Philadelphia: Temple University Press, 1995.

Jindra, Michael \& Noret, Joel Noret, “African Funerals and Sociocultural Change: A Review of Momentuos Transformation Across a Continent." In Funerals in Africa: Explorations of a Social Phenomenon. Eds. Michael Jindra, \& Joel Noret. New York/London: Berghahn Books, 2011.

Lassiter, Valentino. "Homegoings and Crossings: Toward an African-American Theology of Life and Death." In Homegoings, Crossings, and Passings: Life and 
Death in the Diaspora. Ed. Regennia N. Williams, North Ridge-California: New World African Press, 2011.

Lincoln, C. Eric. "Black Religion and Racial Identity." In Racial and Ethnic Identity: Psychological Development and Creative Expression. Eds. Herbert W Harris, et al. New York/London: Routledge, 1995.

Mazzucato, Valentina. "Origins and Destination of Remittances in Ghana." In At Home in the World? International Migration and Development in Contemporary Ghana and West Africa. Ed. Manih, Takyiwaa. Accra, GH: Sub-Saharan Publishers, 2005 .

"Bridging Boundaries with a Ttransnational Research Approach: A Simultaneous Matched Sample Methodology." In Muilti-sited Ethnography. Ed M.A., Falzon. Farnham, MA: Ashgate, Forthcoming.

Mbiti, John S. Introduction to African Religion. $2^{\text {nd }}$ ed. Oxford: Heinemann Educational Publishers, 1975.

Meyer, Birgit. Translating the Devil: Religion and Modernity among the Ewe in Ghana. Trenton: Africa World Press, 1999.

Okorocha, Cyrill C. The Meaning of Religious Conversion in Africa: The Case of the Igbo of Nigeria. Aldershot, BF: Gower Publishing, 1987.

Olupona, Jacob K. "Introduction." In African Immigrant Religions in America. Eds. Olupona, Jacob K. \& Gemiggnani, Regina. New York/London: New York University Press, 2007.

"Communities of Believers: Exploring African Immigrant Religion in the United States." In African Immigrant Religions in America. Eds. Jacob K. Olupona, \& Regina Gemiggnani. New York/London: New York University Press, 2007.

Rey, Terry. Bourdieu on Religion: Imposing Faith and Legitimacy. London: Equinox Publishing Ltd., 2007.

Roosens, Eugeen E. Creating Ethnicity: The Process of Ethnogenesis. New Delhi/London: Sage Publications, 1990.

Royce, Anya P. Ethnic Identity: Strategies of Diversity. Bloomington, IN: Indiana University Press, 1982. 
Sarpong, Peter. Ghana in Retrospect: Some Aspects of Ghanaian Culture. Accra-Tema, GH: Ghana Publishing Corporation, 1974.

Smith, Suzanne E. To Serve the Living: Funeral Directors and the African American Way of Death. Cambridge: The Belknap Press of Harvard University Press, 2010.

Tetteh, Wisdom J. "Transnationlism, Religion, and the African Diaspora in Canada: An Examination of Ghanaians and Ghanaian Churches." In African Immigrant Religions in America. Eds. Jacob K. Olupona, \& Regina Gemiggnani. New York/London: New York University Press, 2007.

Twumasi, Patrick A. Medical Systems in Ghana: A Study in Medical Sociology. Tema, GH: Ghana Publishing Corporation, 1975.

Worku, Nida. "African Religious Beliefs and Practices in Diaspora: An Ethnographic Observation of Activities at an Ethiopian Orthodox Christian Church in Los Angeles." In African Immigrant Religions in America. Eds. Jacob K. Olupona, \& Regina Gemiggnani. New York/London: New York University Press, 2007.

Yankah, Kwesi. Woes of a Kwatriot: Reflections on the Ghanaian Situation. Accra, GH: Woeli Publishing Services, 1990, 17.

\section{Articles}

Dovlo, Elom. "Report on Trokosi Institution." A Report submitted to International Needs in October 1995.

Levit, Peggy \& Schiller, Nina G. "Conceptualizing Simultaneity: A Transnational Social Field a Perspective on Society.” International Migration Review 38 (4): 2004.

Mazzucato, Valentina et al. "Transnational Migration and the Economy of Funerals: Changing Practices in Ghana." Development and Changes 37 (5): 2006.

Owusu, Thomas Y. "The Role of Ghanaian Immigrant Associations in Toronto, Canada." International Migration Review 34 (4): 2000.

Tonah, Steve. "Ghanaians Abroad and Their Ties Home: Cultural and Religious Dimensions of Transnational Migration." A paper presented at the Center for Interdisciplinary Research, Bielefeld, Germany, May 31-June 1, 2007.

van der Guest Sjaak, "Dying Peacefully: Considering Good Death and Bad Death in Kwahu-Tafo, Ghana.” Social Science \& Medicine 58: 2004.

"Between Death and Funeral: Mortuaries and the Exploitation of Liminality in Kwahu, Ghana." Africa 76 (4): 2006. 